\title{
Rehabilitation of torture survivors and prevention of torture: Priorities for research through a modified Delphi Study
}

\author{
Pau Pérez-Sales, MD, PhD, Psych*, Nicola Witcombe, MA, LLM**, \\ Diego Otero Oyague, LPsy ***
}

\begin{abstract}
Background: Research is a key element in prevention and in ensuring that survivors of torture have access to appropriate and effective rehabilitation, but it is often neglected as more pressing issues frequently come first. Methods: A modified Delphi study with three rounds of consultation was used to reach a consensus of expert panellists with respect to top research priorities in the interdisciplinary field of torture rehabilitation and prevention. Panellists included professionals (medical, psychologists and psychiatrists, lawyers, social workers and members of organizations of survivors) from 23 countries balanced by gender, geographical area, profession and area of work (country of asylum versus where torture is perpetrated). Aims were to stimulate an interdisciplinary debate, foster research and inform the future publishing priorities of the Torture Journal (the
\end{abstract}

^) Editor in Chief, Torture Journal, SiR[a] Centre, GAC Community Action Group and Hospital La Paz, Spain.

$\star \star)$ Torture Journal, International Rehabilitation Council for Torture Victims, Copenhagen

$\star \star \star)$ Independent Consultant, Peru

Correspondence to: pauperez@arrakis.es publication which led the study). Findings: The panellists came up with 174 possible lines of research from which 40 were prioritised. Some more theoretical research lines especially regarding neurobiology, evidence-based treatments or ethical debates were not considered a priority. From individual research lines, the four highest ranking were: long-term outcomes and effects of interventions (including chronicity, factors leading to re-traumatisation and implications for public health); outcomes of the Istanbul Protocol (impact of documentation of torture in the judicial system); trans-generational trauma; and, torture in the context of those disappeared and in extrajudicial killings. While there were not significant differences in priorities by gender, the analysis by geographical area showed important peculiarities suggesting that a single worldwide agenda of research might not be realistic or desirable, and that local and regional priorities must be taken into account. Discussion: Overall, the study shows a dissociation between what we know, what we would like to know and what we research. Most of the research published in medical and psychological journals is around local experiences, epidemiological data, case reports and mixed outcome 
studies, which were not among experts' priorities. This points to the fact that existing research can be repetitive and that there is ample scope for other research topics in the future, particularly interdisciplinary research. Conclusion: Whilst it is accepted that global research priorities are unlikely to fully reflect research needs at every level (local/national/regional for example), some important conclusions can be drawn. The anti-torture sector is a fairly young field of academia and is interdisciplinary in nature. A wide scope of research can therefore be usefully undertaken and published for dissemination. It is hoped that the findings of this study may be a useful starting point for consideration and fundraising.

Keywords: Torture rehabilitation, torture prevention, Delphi Study, Pau and Diego, interdisciplinary

\section{Introduction}

There is much to do in the struggle against torture and to ensure that survivors have access to appropriate and effective rehabilitation. Research is a key element in this process, although it is often neglected as more pressing issues frequently come first. In a field were urgency is the norm, research is ethically and methodologically complex (Huggins, 2000; Newman, Willard, Sinclair, \& Kaloupek, 2001). With survivors knocking on the door every day, research seems a secondary element only for welloff centres. But the truth is that there is an ethical responsibility towards those we serve to work according to well-established practices and we lack data (Amris \& Arenas, 2004; Green, Rasmussen, \& Rosenfeld, 2010). Torture evolves constantly and the literature of the 1980s and 1990s needsas in every field - updating. There is a lot of research on the side of perpetrators sponsored by governments under civil or military programs (Llanusa-Cestero, 2010; McCoy, 2008; Physicians for Human Rights, 2010) and the field is rapidly evolving. In a recent review, the first author concluded that there was a ten-year delay between technical and conceptual advances (sic) by perpetrators, and the timid answer from academia and human right activists (PérezSales, 2016 pp 165-7). New methods of torture, more sophisticated, more handsoff, appear. Research has been scarce and often repetitive and the future demands more innovative responses, new impulses and ideas (Manicavasagar et al., 2002). In this process, participation of survivors throughout the process of research is essential (Jackson, 2007)

The torture movement is a young one with significant challenges. Efficacy of treatment has been challenged on different fronts (Başoğlu, 2006; Jaranson, 2006; Miles, 2009; Patel, Williams, \& Kellezi, 2016) and outcome studies can indeed be problematic. From a research point of view, even in very basic studies on efficacy, the generalisability of results is severely undermined by study populations being too heterogeneous and having experienced differing types of torture over differing periods of time and research tools being often too dissimilar (Gurr, R. \& Quiroga, 2001; Jaranson \& Quiroga, 2011). Finally, and from a practical point of view, funding is difficult to obtain for many reasons, not least the political climate where human rights are not prioritised.

A strength and a challenge of the movement is its interdisciplinary nature. This fosters debate and allows torture to be seen from the perspective of the biomedical, forensic, legal, anthropological, social, philosophical etc. However, it is also a challenge. How do we bring these strands together meaningfully? 
The Torture Journal (Journal on Rehabilitation of Torture Victims and Prevention of Torture) is an interdisciplinary, international scientific journal, which seeks to be a forum for the exchange of original research and systematic reviews by professionals concerned with the biomedical, psychological and social interface of torture and the rehabilitation of its survivors. It also seeks to enhance understanding and cooperation in the torture field through diverse approaches. The Torture Journal launched a Delphi Study in order to establish global research priorities with a view to informing the future publishing priorities of the journal and at the same time assisting the wider torture community with a consensus with respect to research priorities (Mikton et al., 2016, Collins et al., 2015). The Delphi Study was intended to be as comprehensive and interdisciplinary as possible by involving experts in the field of prevention and rehabilitation of torture survivors across disciplines, geographical location and gender. Secondary objectives were to stimulate an interdisciplinary debate among different sections of the global movement and to create synergies in future research and publication.

\section{Method}

The Delphi method is a structured methodology to get a collective expert opinion from a panel of specialists who would rarely or never meet physically due to their geographical location and their differing disciplines (Collins et al., 2011, Mikton et al., 2016). It is a useful technique which results in the opinions of a representative sample of experts converging through consecutive rounds of questioning and/or ranking. After each round, a collective feedback of the group's decisions is provided to the group. In successive waves, the experts are encouraged to readjust their earlier answers by taking into account what the group thinks and prioritises. This allows reducing the number of options until a final agreement is made. The mean, median scores or cumulative scores of the final round determine the results.

Thus, to make a recommendation for priority lines of research in the anti-torture sector, we developed a Delphi Study to reach a consensus amongst a representative worldwide panel of experts.

\section{Preliminary round: At a meeting of the} Editorial Advisory Board in 2016, an initial list of research lines was compiled based on research topics through a brainstorming and discussion exercise. Each expert present ${ }^{1}$ was asked to think and name three important research gaps with respect to torture in general and with respect to rehabilitation of survivors specifically, without any further instruction or specific suggestion by researchers. The group produced a set of 119 initial recommendations. The topics and grouping were later e-mailed and corrected by the experts participating in this preliminary round.

Round 1: In February 2017, a wide sample of 154 experts were identified. The involvement of experts across disciplines, geographical location and gender was deemed a priority.

In March 2017, these potential panellists were contacted by email (in English with a

1 S. Megan Berthold (US), Hans Draminsky Peterson (Denmark), James Jaranson (US), Marianne Kastrup (Denmark), June Pagaduan Lopez (Philippines), José Quiroga (Chile/US) , Nora Sveaass (Norway), Morris Tidball-Binz (Argentina), Onder Özkalıpcı (Turkey), Victor Madrigal (Costa Rica), Leanne Macmillan (UK), Pau Pérez-Sales (Spain) 
translation in French and Spanish) and asked if they would participate. The initial step was that they were encouraged - but not required - to review, comment on and edit the initial set of 119 research lines that arose from the preliminary round. For easy reviewing of the potential panellists, the authors divided the list into seven thematic areas.

The feedback obtained from these panellists was collated to avoid duplication and incorporated into the research lines, which meant modification to some with respect to clarity and an overall increase to 174 research lines ('comprehensive list of research topics') and the thematic areas to eight (Annex 1). Email exchange with panellists took place if there was an uncertainty about what they meant.

It was not possible to incorporate all the feedback. For example, some panellists queried the use of so many research lines either because they did not have time to respond to them all, or because they were concerned that the ranking would be so similar that they would not give meaningful results. Some pointed to possible interpretative repetition between lines. This was taken into account when considering the initial findings and whether an additional round was necessary (see below). However, the rationale behind this method was to be as inclusive and comprehensive as possible to the participants.

Round 2: The finalised research lines were sent out to the 62 experts $(40.25 \%$ response rate) who had agreed to take part. This included the 11 members of the Editorial Advisory Board and the Editor in Chief. They were asked to rank the priority of each, with respect to importance, from the point of view of necessity and gaps to fill in the next five to ten years ( 0 : No priority; 1: Little priority; 2: Medium relevant;
3: Maximum priority). Guidelines were given that the priority score was designed to highlight the most important topics of research from the panellist's point of view. They were asked to try to distribute their ranks and give the maximum score (3) to no more than 10 topics overall. There were running totals of maximum priority scores at the end of each section and at the end, however, some panellists did not keep to this guideline which had an effect when deciding to do a third round.

They were also asked to rank feasibility from 0 to 3 (0: Not feasible at this point; 1 : Hardly feasible - needs specific conditions such as a highly specialised centre; 2 : Feasible for an average research centre/ researcher; 3. Feasible even for a nonresearch centre). Guidelines were given that research is feasible when it is technologically or methodologically possible to carry out the research, including related costs and capacity. A topic of research can be a priority but contemporary science does not yet have a realistic capacity to endorse it or there are too many factors involved to have it meaningfully researched.

Panellists received results from previous rounds in an Excel spreadsheet pre-formatted for easy scoring of priorities. The panellists were automatically advised of the number of research lines scored and if there were too many of the total number of high-priority lines selected. The panellists were also asked to provide socio-demographic data, which was subsequently used to analyse the data: Gender; Geographical area of work; Number of years working in the torture field ((0-5, 5-10, 10-15, 15+); Relation to the torture field (Health Professional/ Rehabilitation (e.g. physician, forensic expert, psychiatrist, psychologist, physiotherapist, nurse), or Psychosocial worker (social worker, community worker, facilitator, peer-support 
group, trainer) or Legal professional (legal representative, lawyer, documentation and advocacy)); Primary activity (Direct care or Managerial/legal support/advocacy or Academia/research); Research activity (Published an academic paper in a peerreviewed journal related to the field of torture, Authored a book or report related to the field of torture, Have been a principal investigator in a research involving torture survivors, Participated as a member of a research team); and, finally, whether the panellist works in a country of asylum or a refugee-producing country.

They were also asked whether they considered they had a conflict of interest, and if so, what, and whether the research lines being in English had prevented them from contributing meaningfully.

Thirty-six experts responded initially and a Latin square analysis was carried out based on geographical area and primary activity to identify gaps. In an effort to fill these gaps, follow-up emails were sent to experts as well as to the original 154 experts. Additional efforts to identify new experts were also made. These efforts resulted in five more panellists (see Annex 2 for an overall list of panellists).

Round 3: In this final round, the 62 experts who had originally agreed to take part and the new panellists $(n=67)$ were asked to rank what they considered to be the 10 most important research lines out of a possible 40, and to put them in order of priority (1: least important; 10: most important). In Round 2 feasibility scores did not substantially change priority scores, at least for the top-ranked categories. Thus, for the sake of clarity to panellists, the 40 research lines for Round 3 were derived from the priority score in Round 2. We included those research lines that fell in the top quartile of best ranked answers.
Response rate was high ( $\mathrm{n}=44,65 \%)$. A similar Latin square analysis was undertaken to ensure proper distribution of panellists according to the key independent variables (geographical areas and professional specialities) and individual emails were sent to reinforce participation when significant gaps were detected.

Although the intention was to keep seven geographical areas (Asia, Pacific, Europe, Latin America, Middle East and North Africa, Sub-Saharan Africa and North America), the results forced a different grouping to five areas (Asia, Australia-North America, Europe, Latin America and Africa) to allow for meaningful statistical analysis. Some panellists from Brazil and Argentina discussed their responses with colleagues and indeed some explicitly reported that their responses were the result of a group effort. We decided to respect this decision as a legitimate expression of a collectivistic style of work.

Statistical analysis: To build the global ranking (Table 1), raw scores were derived from the simple sum of the priority values assigned by panellists. Analysis by gender, geographical location, professional profile and the profile of survivors attended was carried out using standardised scores. These were obtained by dividing the raw scores by the number of panellists in each category.

Besides conceptual analysis of topranked research lines by socio-demographic variables, we looked for significant differences by using non-parametric U-Mann Whitney Test for two samples and Kruskal-Wallis Test for multiple groups. Statistical significance was set at 0.05 . While the first gives an overall view of main priorities by sector, the second shows significant differences by line of research. 
Figure 1: Method: Rounds of consultation of experts

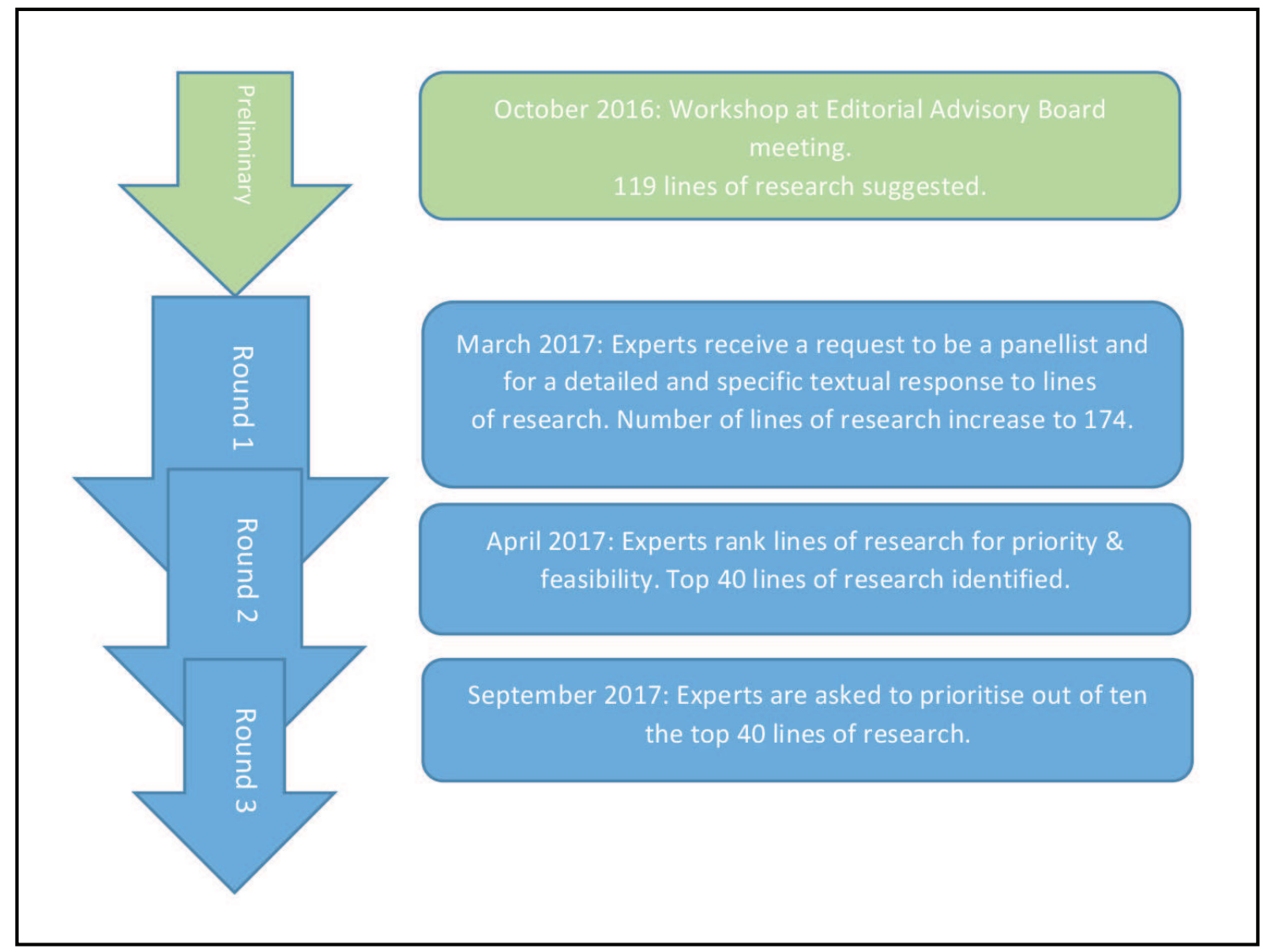

Qualitative considerations: Some qualitative data was captured during Round 2 and 3 as panellists put extra notes and qualifications in their covering emails and in a 'Notes' section next to the research lines. These comments were taken into account by the authors as far as possible when considering the results.

\section{Results}

Following the preliminary round and Round 1, all of the 174 research topics that the group of worldwide experts consider worthwhile researching (Annex 2) were grouped into eight thematic blocks and ranked in Round 2. The wording used by panellists was respected wherever possible. The top quartile of priorities went forward to Round 3 to give a more refined picture.
Table 1 shows the resulting top-ranked research lines.

Table 2 shows a summary of the three top priority lines disaggregated by key variables: gender, geographical area, professional profile and mail profile of survivors attended. A more extended version can be found in Annex 3. Table 3 details statistical differences by line of research.

\section{Discussion}

The results of the study are consistent and show a portrait of the priorities for research in a worldwide and representative multidisciplinary sample of professionals of the health, legal and advocacy fields that work with survivors of torture. In this discussion, an overview of responses will be 
Table 1: Priorities for research-overall sample.

\begin{tabular}{l}
$\begin{array}{l}\text { Pri- } \\
\text { ority }\end{array}$ \\
\hline
\end{tabular}

1 Long-term outcome-Long-term effects of interventions-Cohort studies with survivors. Reactivation of symptoms. "Chronicity" in torture survivors. Factors leading to re-traumatization/"Chronification" (internal and external factors), Implications for public health.

2 Outcomes of Istanbul Protocol. Impact of documentation of torture in the decisions of the judicial system. Does forensic documentation really impact judges in their decisions? Which elements are considered relevant?

3 Trans-generational trauma. Define criteria. Preventive and therapeutic approaches.

4 Torture in the context of those disappeared and in extrajudicial killings (torture resulting in death - denial of information to relatives as torture-Evidence-based data for legal claims as torture). Long-term impact of ambiguous loss-Comparing impact to other forms of torture.

5 Strategic use of clinical data for advocacy. Recommendations and guidelines.

6 Examples of national good policies in the application of General Comment \#3 on the Right to Rehabilitation. Examples of good national plans for integral care of torture survivors. Examples of negative experiences. Recommendations.

$7 \quad$ Psychosocial support to survivors during the legal process. Good practice protocols for survivors that act as witnesses in trials.

8 Survivor participation in setting research priorities and research design. Participatory action research.

9 Critical review and updated data on psychometric tools widely used in the torture sector

10 Providing rehabilitation services in dangerous settings (e.g., when under threat from the state; where torture is rampant, etc.).

11 Minimum standards of good care. What do health professionals and survivors consider a minimum of "good access" to rehabilitation services for torture survivors?

12 Concept/description/Indicators of psychosocial/community impact of torture.

13 Psychological impact of impunity. Paths to recovery where impunity prevails.

14 Tools for quick documentation in police stations, pre-trial detentions and monitoring of prisons.

15 Use of sexual violence in individual torture for both women and men.

16 Models of family interventions.

17 Care for caregivers.

18 Politics and the tightening of asylum law and policies (including mass deportation, increased detention, possibly harder to pass credible fear interview, discriminatory policies toward refugees and asylum seekers from certain religious or ethnic background 
Fight against impunity as a healing process. Meta-analysis/review on the impact of justice on survivors' well-being. Protective and risk elements. Do-no-harm principles and recommendations.

20 Tools for Credibility analysis of the allegations of ill-treatment or torture for supporting survivors' claims.

21 Analysis of the relationship between psychological and somatic symptoms in torture survivors. Chronic pain. Chronic somatic complaints.

23 Impact of judicial interventions on individual well-being. Does access to justice improves quality of life?

24 Survivors of torture and empowerment.

25 What "rehabilitation" of torture survivors means. Defining the field.

26 Dual loyalty. Participation of health professional in torture-Passive support to torture. No documentation of evidence as complicity. Medical role in impunity. Dilemmas and solutions for doctors working under dual loyalty (e.g. the problem of daily attention).

27 Impact of torture by combined or cumulative impacts.

28 Ethical standards in documentation of torture.

29 Relation between different types of torturing environments, impacts on survivors and rehabilitation strategies.

30 Developmental disruptions, long-term impact of relatives' torture, Impact of witnessing torture.

31 Definition. Tools (and validation) for assessing psychological torture.

Definition of torture. Evidence-based distinction between torture and CIDT.

33 Effective implementation of the International Consensus on Minimum Standards for the Psychosocial Work in Exhumation Processes for the Search for Disappeared persons.

34 Victims' priorities regarding types of reparation.

35 Role of media (TV series, films, apps and video games...) in banalizing torture and increasing indifference (bystanders) /support to it.

36 Reasons for supporting/tolerating torture. Increasing support (political, legal, corporative and even social) to the use of torture as shown by polls and sociological studies.

37 Patterns of torture based on political contexts and analysis of conditions where there is a heightened risk of torture?

38 Beyond torture methods - Definition of Torturing Environments. Rehabilitation services 
analysed first, followed by the specific top lines of research.

\section{Opening the lens: global perspectives arising from the study: Overall tendencies}

The initial exercise of collective brainstorming provided a set of 174 possible lines of research.
Whilst there was some overlap between lines of research and more than one research idea could be found in an item, this reflects an intention to be true to the wording and responses of the panellists. Despite this, it shows an astonishing richness of ideas. Rather than showing that there is nothing new to research, it shows that there are

Table 2: Comparison by key variables (original research line number-min=0; max $=100$ )

\begin{tabular}{|c|c|}
\hline \multirow{3}{*}{$\begin{array}{l}\text { Gender } \\
\text { Female }\end{array}$} & Long-term outcome--Long-term effects of interventions (124-31) \\
\hline & Trans-generational trauma $(22-30)$ \\
\hline & $\begin{array}{l}\text { Examples of national good policies in the application of General Comment } \\
\text { the Right to Rehabilitation (86-29) }\end{array}$ \\
\hline \multirow[t]{3}{*}{ Male } & Long-term outcome- - Long-term effects of interventions (124-43) \\
\hline & Outcomes of Istanbul Protocol (73-35) \\
\hline & Survivor participation in research. Participatory action research. (128-24) \\
\hline Geographical & Does access to justice improve quality of life? (132-70) \\
\hline Distribution & Impact of torture by combined or cumulative impacts $(5-53)$ \\
\hline \multirow[t]{3}{*}{ Asia } & Psychometric tools $(6-50)$ \\
\hline & Outcomes of Istanbul Protocol. Impact of documentation of torture in the \\
\hline & Tools for Credibility analysis $(70-43)$ \\
\hline
\end{tabular}

Europe

Long-term outcome-Long-term effects of interventions (124-45)

Outcomes of Istanbul Protocol (73-38)

Strategic use of clinical data for advocacy (174-27)

Survivor participation in setting research priorities and research design (128-23)

Examples of national good policies (86-22)

Latin America Long-term outcome-Long-term effects of interventions (124-61)

Torture in the context of those disappeared and in extrajudicial killings (27-60)

Trans-generational trauma (22-54)

Examples of national good policies (86-50)

Psychosocial support to survivors during the legal process (141-34)

África and Middle

Psychometric tools (56-31)

East

Strategic use of clinical data for advocacy (174-30)

Care for caregivers (119-29)

Models of family interventions (101-28)

Providing rehabilitation services in dangerous settings (83-28)

North America and Pacific
Strategic use of clinical data for advocacy (174-33)

Politics and the tightening of asylum law and policies (171-31)

Survivor participation in setting research priorities and research design (128-30)

Minimum standards of good care in rehabilitation services (88-30)

Long-term outcome - Long-term effects of interventions (124-27) 


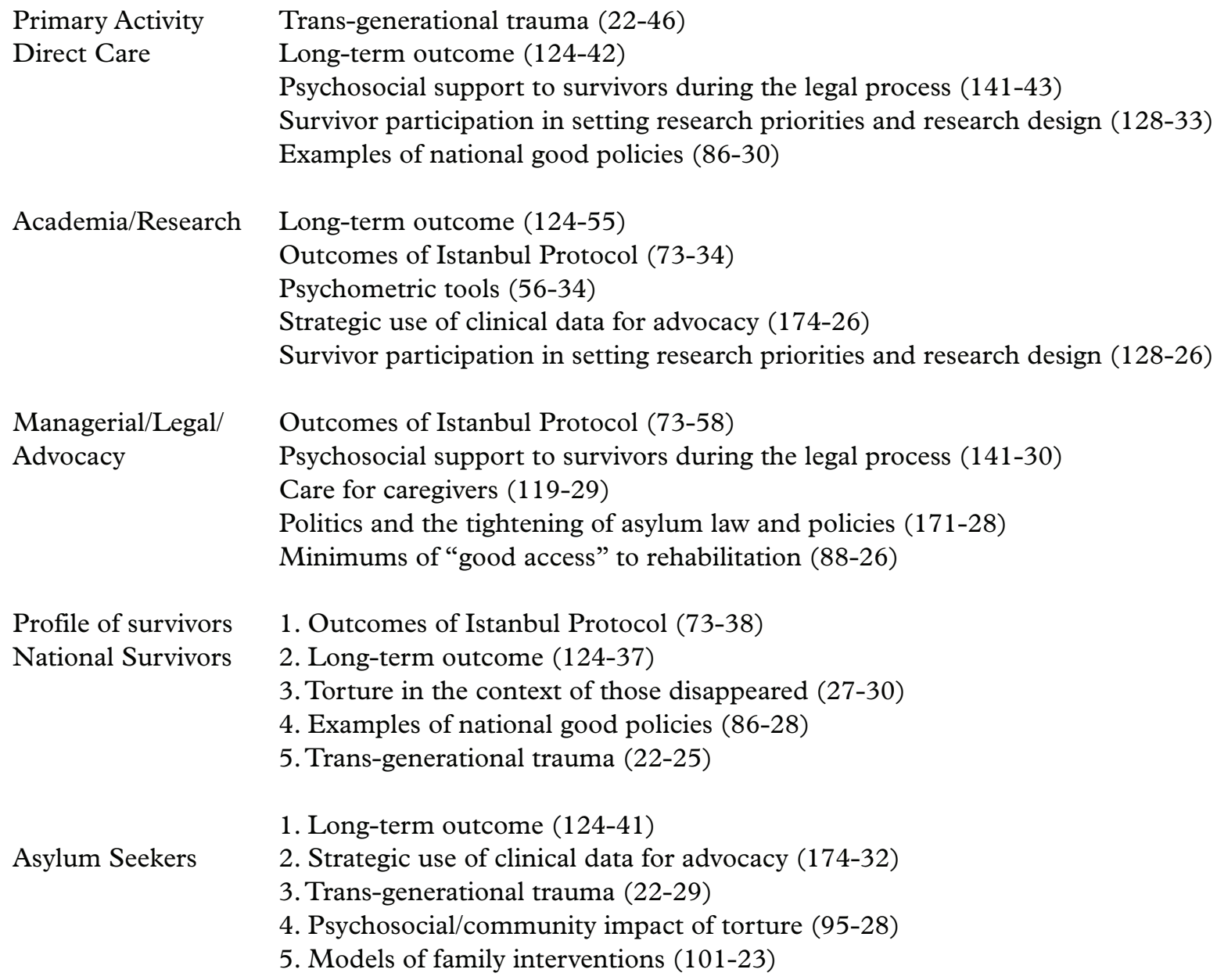

more doubts than certainties and much still to do. Reviewing what the panellists suggested as relevant lines of research against the backdrop of the available literature (including the indices of the Torture Journal) as a barometer of what is being researched in the field, most of them are simply not present. In other words, there is a dissociation between what we know, what we would like to know and what we research. Most of the research published in medical and psychological journals is around local experiences, epidemiological data, case reports and mixed outcome studies. There appear to be many more research questions that panellists think have not been answered yet. This points to the fact that existing research can be repetitive and that there is ample scope for other research topics to be the focus in the future.

This does not mean that others are not doing research on some of these topics that scarcely appear in our publications. For instance, in the field of interrogation of detainees there has been much advancement in recent years, but limited to specific research groups of forensic psychologists not specifically linked to the field of torture research. Additionally, it may reflect the fact that some potential researchers/researcherpractitioners are unable to participate due to political, security or resource issues. Part of the gap between what we know and what we want to know could be solved if we were 
Table 3: Statistical differences by line of research according to key socio-demographic variables (original research line number)

\begin{tabular}{|c|c|c|c|}
\hline & $\begin{array}{l}\text { Line of research } \\
\text { (code as referenced in Annex 1) }\end{array}$ & M / Group & $\mathbf{p}$ \\
\hline \multirow[t]{2}{*}{ Gender } & Care for Caregivers (119) & Female 2.19 , Male 0.50 & 0.03 \\
\hline & Sexual violence (13) & Female 1.96, Male 0.65 & 0.05 \\
\hline \multirow{9}{*}{$\begin{array}{l}\text { Geographi- } \\
\text { cal Area }\end{array}$} & Torturing environments (4) & Africa & 0.016 \\
\hline & $\begin{array}{l}\text { Relationship between torturing environments } \\
\text { and clinical impacts in survivors (6) }\end{array}$ & Africa, Europe & 0.012 \\
\hline & Sexual violence (13) & Africa & 0.037 \\
\hline & Torture in forced disappearance (27) & Latin America & 0.016 \\
\hline & Models of family intervention (101) & Africa & 0.03 \\
\hline & Care for caregivers (119) & Africa & 0.022 \\
\hline & $\begin{array}{l}\text { Impact of judicial interventions on well-being } \\
\text { (132) }\end{array}$ & Asia, Latin America & 0.043 \\
\hline & Role of Media (167) & Asia & 0.003 \\
\hline & $\begin{array}{l}\text { Politics and the tightening of asylum law } \\
\text { and policies (171) }\end{array}$ & North America-Pacific & 0.05 \\
\hline \multirow{7}{*}{$\begin{array}{l}\text { Primary } \\
\text { Activity }\end{array}$} & Transgenerational trauma (22) & Direct Care & 0.005 \\
\hline & Torture in forced disappearance (27) & Direct Care & 0.009 \\
\hline & Psychometric tools (56) & Academia & 0.020 \\
\hline & Impact of Istanbul Protocol (73) & Legal-Advocacy & 0.016 \\
\hline & Long-term outcome (124) & Academia + Direct Care & 0.002 \\
\hline & $\begin{array}{l}\text { Victim's priorities regarding types of } \\
\text { reparation (146) }\end{array}$ & Academia & 0.049 \\
\hline & $\begin{array}{l}\text { Strategic use of clinical data for advocacy } \\
\text { (174) }\end{array}$ & $\begin{array}{l}\text { Academia + Legal- } \\
\text { Advocacy }\end{array}$ & 0.005 \\
\hline \multirow{2}{*}{$\begin{array}{l}\text { Profile of } \\
\text { survivors }\end{array}$} & Developmental disruptions (18) & Asylum & 0.040 \\
\hline & Intersection between justice and rehabilitation & National & 0.026 \\
\hline
\end{tabular}
(131)

able to work in a more interdisciplinary way, integrate knowledge from other fields and were able to read and learn more from connected disciplines and perhaps bridge the gap to useful data sets that never see the light of day and to potential researchers who against their own wishes do not have a voice.

Before turning to the priorities, it is of value to review what has not been considered a priority. It is note-worthy that the topics prioritised by the panellists reflect a focus on quite classical topics of interest in the field. New or ground-breaking topics -including most of those addressed in the last few thematic reports by the UN Special
Rapporteurs - were actually discarded in the early rounds. These included research related to gender perspectives (items 10-12, 14); torture in health institutions (items 15-17); coercive versus cognitive interviewing (item 7); torture linked to social cleansing policies (23-24); torture in demonstrations and other non-custodial settings (26-30, 44-47); torture and migration (30-31,34,75, 117,118); solitary confinement and torture in prisons (39$42,121)$; neurobiology of torture (48-49); use of new technologies (50-51); relationship between PTSD, trauma and torture (63-64); early identification of victims and 
documentation of torture in massive atrocities $(67,74,79)$; updating, adapting or strengthening the Istanbul Protocol $(69,77,78)$; medical and pharmacological treatment based on evidence $(102,103$, 105-110); cultural meaning of torture (111-116); implementation and efficacy of National Prevention Mechanisms (149, 151) or implementation of international databases (173).

It is possible to speculate over the reasons behind these notable absences. These topics may of course still be of interest to panellists, but may not be considered a priority for a host of reasons, including that they are aware of research already being undertaken. The anti-torture sector (if our sample is to represent it) encompasses many different contexts, from a field worker who carries out basic psychosocial and counselling activities in a dangerous context, to a therapist from the global north who does expressive therapies with asylum seekers, from a lawyer that does strategic litigation of selected cases, to a neurobiologist that does empirical research on brain tissue damage, from a human rights organization doing country reports to torture survivors who speak out. This being so, it may be that some of the topics were only a priority to a statistically insignificant number of, or at least fewer, panellists, or those interested in those topics were not sufficiently represented in the sample.

While recent literature on the neurobiology of torture has been among the most innovative and influential (Elbert et al., 2011; O’Mara, 2016) panellists may see this as unrelated to their everyday concerns. This is the case even when feasibility is not an issue; including feasibility as a measure did not change the limited importance given to this kind of research by our panellists suggesting that it is not a coincidence that neurobiological research is only considered a possibility by the fewest of the major research centres. The only (limited) exception pointed out by two panellists is when neurobiology can help in better defining torture, in determining the difference between torture and CIDT, or in documenting torture for legal processes. This may reflect a tendency in the sector to delay in responding to state-of-theart thinking, which is a concern in an environment where a significant proportion of military research spending goes to basic psychological research (Intelligence Science Board, 2006). There is a similar tendency with new technologies on how the brain, human consciousness and human will can be manipulated and controlled and the implications in terms of cognitive liberties and new generations of human rights. This deserves some reflection, at least in research centres where this kind of research is viable.

Turning to what has been prioritised, we find the definition of torture versus CIDT (1); specificities of contemporary torture and torturing environments $(4,5,6,60)$; specificities of certain populations -sexual violence, children and transgenerational trauma, extrajudicial killings and forced disappearance $(13,18,22,27)$; documentation of torture (43), and impact on the judicial system (73); definition of rehabilitation and good practices $(82,83,86,88,92,124)$, measures, questionnaires $(56,59,70,76)$; community indicators (95); empowerment of victims $(128,130)$; impunity, justice and redress $(131,132,138,141,142,146,148)$; ethical aspects $(148,152)$; and political and sociological aspects $(165,167,170,171)$.

Although the overall picture shows great heterogeneity, in reviewing manually experts' responses one by one, it is possible to discern that what has clearly been prioritised is practice over theory; most panellists have ranked not according to a global idea of the 
priorities of the anti-torture movement, but according to one or more aspects of their direct needs related to their primary activity (see Annex 3 for top priorities by sociodemographic variables).

Although there is a strong emphasis on treatment and rehabilitation issues, when this category is scrutinised in more detail, experts show an interest in what "rehabilitation" means, national policies in the application of General Comment \#3 of the CAT regarding the duty of the State to provide reparation measures, including full rehabilitation of victims. ${ }^{2}$ This opens the debate on how this reparation and rehabilitation should be provided and dilemmas on the dual role of the State as perpetrator and provider of help and the role of independent organizations which have been providing legal advice and health services for decades. While this has a clear advocacy side, the importance given by panellists to this line of research may also reflect the critical financial situation of many of these centres and the dangers of being absorbed by the State and eventually closed depending on political priorities and policies. It may also reflect the debate on the minimum standards of

2 General Comment \#3 of the United Nations Committee against Torture was published in December 2012 and is devoted to the implementation of article 14 of the Convention that says that each State party is required to "ensure in its legal system that the victim of an act of torture obtains redress and has an enforceable right to fair and adequate compensation, including the means for as full rehabilitation as possible". The Comment also states "that a person should be considered a victim regardless of whether the perpetrator of the violation is identified, apprehended, prosecuted or convicted, and regardless of any familial or other relationship between the perpetrator and the victim." It establishes the highest possible standard in the duty of the State to repair and specifically, to provide rehabilitation. rehabilitation and what can be considered good practice at the national level as well as links and coordination with existing mental health services.

National policies are, in fact, considered more important than research into working in complex and unstable contexts, particularly by experts from the global north. However, this may also reflect a concern that needs of torture survivors are best met through long-term, structural support. Somewhat surprisingly, the panellists either do not show a great interest in the best therapeutic models or they believe this research has already been done or is being done. The obsession for so-called evidence-based treatments and guidelines of good practice shown by some academia and especially by funders, seems not to be shared by most of the experts. There is only some concern for pain and somatic unexplained symptoms and the interplay of body expressions of distress, and in a better definition and measurement of psychological torture. These are unresolved challenges in current therapeutic models. In response to panellists' general lack of prioritising shortterm, evidence-based outcome studies, it is tempting to say that most practitioners have the idea that what they do is simply correct because it comes from years of therapeutic experience, but this is of course open to debate; some therapies, which still have insufficient research support in the work with torture survivors (like Narrative Exposure Therapy, Cognitive Behaviour Therapy or Psychological First Aid) (Dieltjens et alt 2014; Patel, Kellezi, \& Williams Amanda, 2011) are often adopted uncritically and arguably prematurely considered as evidence-based, possibly reflecting the need to validate practice in front of donors and out of a need to belong to mainstream practices. Using 
trans-theoretical paradigms, most of the models that are the subject of research are in fact manualised variations on the same traditional narrative techniques that therapists have been doing for decades (Perez-Sales, 2017). Some experts might have a more humanistic, existentialist approach and do not consider relevant to their practice to undertake case-control studies of manualised therapies. This being so, common sense solutions represented by quite flexible and patient-tailored modular treatments in which the therapist chooses among different packages according to the survivors needs seem to be one of the most promising options for the future (Bolton et al., 2014; Murray et al., 2014).

There is also a strong concern with justice and redress, not only from legal professionals. While there is a wealth of clinical literature and essays linking impunity with damage and re-traumatization and analysing justice as a healing factor (Rojas, 2017), experimental studies demonstrating that this is so, including considering optimal conditions for specific profiles of survivor and their specific needs in this process and how to properly address the relation of justice and well-being, are virtually nonexistent. This is a neglected field of research, perhaps because the importance of the fight against impunity seems so self-evident on the one hand, but concrete data remains difficult to capture, something which our experts stress. Many panellists also show a strong interest in the interplay between the legal and medical world, especially the relationship between documentation of medical and physical consequences, rehabilitation and justice. One topic stands out in the responses: the impact of the documentation of torture (and particularly the Istanbul Protocol) on legal processes, especially from European panellists. This will differ within jurisdictions and their diverse evidentiary rules, as well as on the national, regional and international level. Additionally, there are other specific points of concern (132-134): the process of justice in itself (independent of the sentence) as a no-harm and eventually healing process and best practices in working in support of victims during the legal process.

Advocacy is also deemed important in the overall picture, especially regarding the use of clinical data for activist purposes. While $60 \%$ of the panellists work in Europe, North America and Australia there is scarce interest in research involving refugees and asylum seekers, apart from political advocacy which is a concern for North American panellists, but not for European experts nor for professionals working with internal displacement or migrants in the global south. The so-called European crisis does not appear to have had an influence on priorities for research, at least in this study. This is surprising when this topic represents a vast majority of what most journals (the Torture Journal among them) have been receiving as submissions, giving cause for reflection. One hypothesis for this seemingly surprising fact is that a lot of research done in this area involves replicating very basic epidemiological or general-purpose unspecific outcome studies that often do not give new or insightful results. This can be called opportunistic research and is not intended to answer complex or novel questions. By contrast, the topic of torture in democracy, contemporary torture and the effect of combined and cumulative effects of torture and the definition of torturing environments are deemed important by panellists and considered important priorities.

Debates on ethical aspects of torture also attract little attention. This is in contrast with what readers will find in their 
bookstore: approximately seven out of ten books published in the last ten years on torture are related to ethical or philosophical debates on whether torture is justifiable or not under certain conditions.

\section{The fine picture: scope of research lines}

If, instead of overall tendencies, we consider research lines (Table 1) our panellists clearly point to five main topics for future research:

(1) The first topic is the consequences of torture as a chronic disease (124). This includes research on factors that lead to re-traumatisation or "chronification", and that can make an identity to be built around victimhood. This refers to symptoms that can evolve depending on psychosocial circumstances but that need a long-term overview. Panellists are concerned by what happens with untreated torture survivors over time, factors for relapse and implications in terms of public policies. The experience of long-running treatment centres (like those linked to the PRAIS program in Chile, to name one example) gives support to the idea that, at least for a substantial proportion of survivors, symptoms are latent.

(2) The second topic is outcomes of the forensic documentation of torture in general and the Istanbul Protocol in particular (73). A great deal of time in rehabilitation centres is devoted to documenting torture for legal processes, such as, asylum claims, strategic litigation or defending victims from self-indictments under torture (Hass, 1990). This brings with it a host of implicit questions: Are the efforts in, for example, the use of the IP and training of judges/prosecutors/ police influencing individual court decisions and wider judicial practice?
What aspects are genuinely considered by judges and administrators? Does the quality of the evidence provided make a difference? How can we better adapt forensic work to these legal tasks? Our panellists stress the importance of some of these and other inter-related issues, such as, credibility analysis in the allegations of ill-treatment and torture, and the documentation in complex environments, especially police stations and prisons $(70,76)$.

(3) A third topic of legitimate concern in many geographical areas is related to second and third generation effects, which is the next top-rated topic of concern for panellists (22). While there have been research studies in survivors of the Holocaust since the 1960s and especially in the 1980s and 1990s (Hass, 1990; Hogman, 1998), this is an emerging topic in Latin America (CINTRAS, EATIP, GTNM/RJ, 2009), Asia (Daley, 2006; Dalgaard \& Montgomery, 2015) MENA (Fritzemeyer, 2017) and in African countries (Daud, Skoglund, \& Rydelius, 2005) (Baum, 2013).

Most of this research involves clinical description, models of family therapy or qualitative unstructured descriptions. The methodological and conceptual challenges of this kind of research are enormous and undoubtedly in an epoch where the links between early attachment and trauma are also at the foreground of research.

(4) The panellists consider research on torture linked to forced disappearance a priority (60). Interestingly, no academic journal specifically addresses this topic and it is often not considered as a key topic in symposia on rehabilitation of torture survivors. This unexpected and very important finding must be discussed with a view to potentially widening the 
scope of the Torture Journal to include forced disappearance, extrajudicial executions and working with mass graves, along with research done by groups and organizations working on these topics.

(5) Finally, panellists were concerned about the use of databases for research and advocacy (172). When in a globalised world we are aiming to build large databases connecting different sources of data and make them available to researchers, how can this be translated into real change when working with torture survivors? Classical clinical databases gather mainly epidemiological information that provides a picture of what is out there; how many cases, with what profile and shows tendencies. Advocacy demands a different kind of database that might allow researchers to make links with the social and political environment. However, as more variables are included, the more difficult it is for users, who are usually busy clinicians unless there is a body of researchers and funding support. A kind of compromise is needed. Finally, the technical and security challenges of human rights' databases are also a challenge in the sense that whilst data needs to be available for advocacy purposes, it also needs to be adequately protected and anonymised. There is undoubtedly rich opportunity here and the panellists seem to demand more work in this area.

\section{Analysis by socio-demographic data}

By enlarge, the analysis by sociodemographic data showed little meaningful variation, which may have been a result of the size of the sample (See Annex 3 for the top ranked 40 lines by socio-demographic data). Nonetheless, it added depth of understanding in some important research lines (such as that with respect to forced disappearances (see below)).

Differences between groups: There are slight differences by gender (Annex 3). There is some reordering of top priorities, but this is difficult to interpret and may be due to an unequal distribution of gender by geographical area (more females in Latin America and Europe as compared to MENA and sub-Saharan Africa).

Geographical Distribution: In countries where violence is seen as part of the recent past, concerns were related to long-term outcome and rehabilitation policies. There was no clear pattern in North America-Pacific (probably due to the small sample size). Panellists from Europe rank in line with the overall sample. In Latin America, significant differences appeared: greater importance was given to work with the disappeared, with a greater focus on the relationship between impunity, justice and healing, long-term outcomes and transgenerational trauma (especially taking into account the time elapsed since many Latin American dictatorships ended), and psychosocial and community perspectives. In the Middle East and North Africa panellists were more concerned with therapy: working with survivors of sexual violence and working with somatic complaints besides a strong emphasis on legal and forensic working and supporting victims. This was entirely different in sub-Saharan Africa where the priorities were caring for caregivers and family work, probably in relation to working in complex and unstable contexts and the importance of family in the African context. Finally, in the North America there was a concern with advocacy linked to refugees, possibly connected to their day-to-day work at an historical moment of very hard governmental 
policies against migrants and survivors of torture. All these are examples showing that a single worldwide agenda of research might not be realistic or desirable. While there is the need for some universal shared priorities, research must also tackle regional and national local concerns (Table 2).

Primary activity: Again, there are more similarities than differences when comparing the top five priorities for professionals who undertake direct care, academia-research and legal and advocacy activities, probably linked to the fact that most of our panellists combine two or more of these activities and, in any case, share the same analysis and plans in multi-professional teams.

Profile of survivors: Both professionals working in asylum or with national victims show a similar profile, similar to that of the general sample.

\section{Limitations of the study}

The study shows a unique perspective of what the anti-torture sector considers priorities for research. The results, as with any Delphi exercise, depend on the selection of panellists. Any effort to make a representative sample depends on the actual responses received. Our study might show a slight overrepresentation of European experts and of professionals doing direct care with survivors. This might have affected the overall results, and is only partially compensated by a detailed analysis by key variables.

In Round 2, the number of research lines (174) was overwhelming and may have resulted in a lower response rate than had there been fewer research lines. That said, the number of responses were not significantly different for Round 3, when only the top 40 research lines were used. Using an Excel spreadsheet was perhaps cumbersome compared to using an online survey option. However, it was felt that, given the high number of research lines and that the hope was to reach panellists who perhaps do not have consistent internet access, that this was the best method. Furthermore, an online survey option may perhaps have increased the response rate.

As shown in Annex 2, samples from Round 2 and 3 are mostly the same, but some panellists only responded to one round or the other. The Latin square analyses was used to maintain the balance and representativeness of the sample as far as possible.

\section{Conclusion}

Delphi methodologies are always exploratory and intended to provide guidelines and food for thought. They are an attempt to quantify the shared priorities of a representative sample of experts in a certain field. This study is, to our knowledge, the first done in the field of prevention and rehabilitation of torture. It shows that providing definitive research priorities for an interdisciplinary, heterogeneous and global group is challenging. The current study suggests that there is a dissociation between what we know, what we would like to know and what we research, and that there are important gaps of knowledge. It also shows that, although a uniform set of priorities may not be meaningful for every local or even regional context, there is some consistency. We expect that the results can provide a guiding light for the Torture Journal in the coming years, and we hope that research projects will not only become a reality, but that the research lines set out in this study can inspire academics and professionals in human rights and rehabilitation centres. The Torture Journal, as the interdisciplinary academic journal of reference to the antitorture community, will surely try to foster and publish research along these lines. 
Whilst this holds true, it is important to stress that the study may not have reflected the richness of possible and necessary research in its entirety and there remains some very important absences. Most experts had over 15 years of experience of working with torture survivors and their responses were largely based on their professional experience. More theoretical fields may have naturally fallen outside their immediate areas of interest. It is important to reflect on the fact that the field is a rapidly evolving one with new advances and an emphasis on psychological coercion rather than physical pain, which frequently demands flexibility and adaptability from researchers. That being so, the comprehensive list originally compiled can assist in setting future publication priorities for the journal as well as being useful in wider discussions in different contexts, not least in stimulating debate in what are the next steps in building a sector that can respond to the changing and demanding environment in which most of us work.

\section{Acknowledgements}

The authors would like to thank Leanne Macmillan, the former Director of Research Development of the IRCT for her support and insight.

\section{References}

Amris, S., \& Arenas, J. (2004). Impact assessment in rehabilitation of torture survivors. -- A long-term research strategy based on a global multi-centre study design. Part I: Theoretical considerations. Psyke E Logos, 25, 37-76.

Başoğlu, M. (2006). Rehabilitation of traumatised refugees and survivors of torture. BMF: British Medical fournal, 333(7581), 1230-1231. https:// doi.org/10.1136/bmj.39036.739236.43

Baum, R. (2013). Transgenerational trauma and repetition in the body: The groove of the wound. Body, Movement and Dance in Psychotherapy, 8(1), 34-42. https://doi.org/10.1080/17432979. 2013.748976
Bolton, P., Bass, J. K., Zangana, G. A. S., Kamal, T., Murray, S. M., Kaysen, D., ... Rosenblum, M. (2014). A randomized controlled trial of mental health interventions for survivors of systematic violence in Kurdistan, Northern Iraq. BMC Psychiatry, 14(1), 360. https://doi.org/10.1186/ s12888-014-0360-2

CINTRAS, EATIP, GTNM/RJ, S. (2009). Daño transgeneracional. Consecuencias de la represion politica en el Cono Sur [Trasngenerational harm: Consequences of political repression in the South Cone]. Santiago: LOM Editores.

Collins, P.Y., Patel, V., Joesti, S.s., March, D., Indel, T.R., \& Darr, A.S. (2011) Grand challenges in global mental health. Nature 475(7354): 27-30 DOI: $10.1038 / 475027$ a

Daley, T. C. (2006). Mental health issues among second generation cambodian children and communication processes with their parents. Dissertation Abstracts International: Section B: The Sciences and Engineering.

Dalgaard, N. T., \& Montgomery, E. (2015). Disclosure and silencing: A systematic review of the literature on patterns of trauma communication in refugee families. Transcultural Psychiatry, 52(5), 579-593. https://doi. org/10.1177/1363461514568442

Daud, A., Skoglund, E., \& Rydelius, P.-A. (2005). Children in families of torture victims: transgenerational transmission of parents' traumatic experiences to their children. International fournal of Social Welfare, 14, 23-32. https://doi.org/10.1111/ j.1468-2397.2005.00336.x

Dieltjens, T., Moonens, I., Van Praet, K., De Buck, E., \& Vandekerckhove, P. (2014). A Systematic Literature Search on Psychological First Aid: Lack of Evidence to Develop Guidelines. PLoS ONE, 9, e114714. https://doi.org/10.1371/journal.pone.0114714

Elbert, T., Schauer, M., Ruf, M., Weierstall, R., Neuner, F., Rockstroh, B., \& Junghöfer, M. (2011). The Tortured Brain. Zeitschrift Für Psychologie, 219(3), 167-174. https://doi.org/10.1027/21512604/a000064

Fritzemeyer, K. (2017). “... yes, it's difficult, because we have to satisfy her heart"Exploring Transgenerational Effects of Collective Persecution and Genocide in Kurdistan-Iraq. International Fournal of Applied Psychoanalytic Studies, 14(1), 7-21. https://doi. org/10.1002/aps.1513

Green, D., Rasmussen, A., \& Rosenfeld, B. (2010). Defining Torture : A Review of 40 Years of Health Science Research What Are the Definitions of Torture Used in the Scientific How Is 
Severity of Torture Conceptualized and. Fournal of Traumatic Stress, 23(4), 528-531. https://doi. org $/ 10.1002 /$ jts.

Gurr, R. \& Quiroga, J. (2001). Approaches to torture rehabilitation. Torture, 11(Supplement 1:1-35).

Hass, A. (1990). In the shadow of the Holocaust. The second generation. Cambridge University press.

Hogman, F. (1998). Trauma and identity through two generations of the Holocaust. Psychoanalytic Review, 85(4), 551-578.

Huggins, M. (2000). Reconstructing atrocity: How torturers, murderers, and researchers deconstruct labels and manage secrecy. Human Rights Review. https://doi.org/10.1007/s12142-000-1043-6

Intelligence Science Board. (2006). Educing Information Interrogation: Science and Art. (D. L. S. Robert Destro, Robert Fein, Pauletta Otis , John Wahlquist, Robert Coulam, Randy Borum, Gary Hazlett, Kristin E. Heckman and Mark D. Happel, Steven M. Kleinman, Ariel Neuman and Daniel Salinas-Serrano, Ed.). Washington DC: National Defense Intelligence College Press.

Jackson, L. E. (2007). From torture to treatment: A constructivist leadership participative action research approach to curriculum development for paraprofessional training to provide community mental health services in post-Saddam Iraq. Dissertation Abstracts International Section A: Humanities and Social Sciences. Retrieved from http://search.ebscohost.com/login. aspx?direct $=$ true $\& \mathrm{db}=$ psyh $\& A N=2007-99001$ $001 \&$ site $=$ ehost-live

Jaranson, J. M. (2006). Rehabilitation of traumatised refugees and survivors of torture: a reply to Basoglu. BMF, 333(7581), 1230-1231. https:// doi.org/10.1136/bmj.39036.739236.43

Jaranson, J. M., \& Quiroga, J. (2011). Evaluating the services of torture rehabilitation programmes: history and recommendations. Torture : Quarterly Fournal on Rehabilitation of Torture Victims and Prevention of Torture, 21(2), 98-140.

Llanusa-Cestero, R. (2010). Unethical research and the C.I.A. Inspector General Report of 2004: observations implicit in terms of the common rule. Accountability in Research, 17(2), 96-113. https://doi.org/10.1080/08989621003708493

Manicavasagar, V., Silove, D., Tang, K., Aroche, J., Steel, Z., Chaussivert, M., ... Coello, M. (2002). Towards a Researcher-Advocacy Model for Asylum Seekers: A Pilot Study Amongst East Timorese Living in Australia. Transcultural Psychiatry. https://doi. org/10.1177/1363461502039004491

McCoy, A. W. (2008). Legacy of a dark decade: CIA mind control, classified behavioral research and the origins of modern medical ethics. In A. Ojeda (Ed.), The trauma of psychological torture. Praeger Publisher.

Mikton, C.R., Tanaka, m., Tomlinson, m., Streiner, D.L., Tonmyr, L., Lee, B.X., Fisher, J., Hegadoren, K., Pim, J.E., Sharlenna Wang, S.J., \& Macmillan, H.L. (2016) Global research priorities for interpersonal violence prevention: a modified Delphi study Bulletin of the World Health Organization 95:36-48 http://dx.doi. org/10.2471/BLT.16.172965

Miles, S. H. (2009). Profane Research Versus Researching the Profane: Commentary on Ba oglu (2009). American fournal of Orthopsychiatry, 79(2), 146-147. https:/doi. org/10.1037/a0015680

Murray, L. K., Dorsey, S., Haroz, E., Lee, C., Alsiary, M. M., Haydary, A., ... Bolton, P. (2014). A Common Elements Treatment Approach for Adult Mental Health Problems in Low- and Middle-Income Countries. Cognitive and Behavioral Practice, 21(2), 111-123. https://doi. org/10.1016/j.cbpra.2013.06.005

Newman, E., Willard, T., Sinclair, R., \& Kaloupek, D. (2001). Empirically supported ethical research practice: the costs and benefits of research from the participants' view. Accountability In Research, 8(4), 309-329. Retrieved from http://ovidsp.ovid. com/ovidweb.cgi? $\mathrm{T}=\mathrm{JS} \& \mathrm{PAGE}=$ reference $\& \mathrm{D}=\mathrm{m}$ ed $4 \&$ NEWS $=\mathrm{N} \& A N=12481796$

O'Mara, S. (2016). Why torture doesn't work. The neuroscience of interrogation. Harvard University Press.

Patel, N., Kellezi, B., \& Williams Amanda, C. D. C. (2011). Psychological, social and welfare interventions for psychological health and well-being of torture survivors. Cochrane Database Of Systematic Reviews, 10. https://doi. org/10.1002/14651858.CD009317

Patel, N., Williams, A. C. D. C., \& Kellezi, B. (2016). Reviewing outcomes of psychological interventions with torture survivors : Conceptual , methodological and ethical Issues. Torture fournal, 26(1), 2-16.

Pérez-Sales, P. (2016). Psychological torture: Definition, evaluation and measurement. Psychological Torture: Definition, Evaluation and Measurement. https:// doi.org/10.4324/9781315616940

Physicians for Human Rights. (2010). Experiments in torture : Evidence of human subject research and experimentation in the "Enhanced" Interrogation Program. Washington: Physicians for Human Rights.

Schiemann, J. (2016). Does torture work? Oxford University Press. 


\section{Annex I}

Lines of research from Round 2 in eight categories

Area Sub-group Research line

\section{(1) CONCEPTS, POPULATIONS AND METHODS}

\section{Definition}

1 Definition of torture. Evidence-based distinction between torture and CIDT. United Nations definition vs others (I,e Amnesty International)

2

How to define torture in resilient individuals. Survivors that have endured multiple torture events for 15 years or more. Implications for the "suffering" criteria.

3

How the consideration of new groups of survivors as falling in the definition of torture affects the definition-better definitions for special groups. How these new groups change the social perception of torture.

\section{Contemporary torture}

4

5

6

7

8

Beyond torture methods - Definition of Torturing Environments.

Impact of torture by combined or cumulative impacts.

Relation between different types of torturing environments, impacts on survivors and rehabilitation strategies.

International standards in the interrogation of detainees. Coercive versus cognitive interviewing.

Is torture useful? Is it an effective method in eliciting information from a detainee?. Confirmatory studies in different interrogational settings

Victim groups, locations, types of torture, specific vulnerabilities risks, impacts and needs

Gender Methods of torture specific to women and specific impacts.

Perspectives

10

11

12

13

14
Trafficked women and torture and other forms of torture by non-state actors

Mother separated from their babies for minor infractions as torture.

Torture related to LGBTIQ identity

Use of sexual violence in individual torture for both women and men.

Collective rape in political conflict. Proper evidence collection and documentation. 
Health-Care, Social Services, Geriatric

Settings

\section{Children}

Forced displacement I Refugees / Migration
Torture in health institutions (especially non-medical treatment of drug addicts).

Elderly - Ill-treatment in involuntary admissions of elderly people. Diagnostic challenges in geriatric institutions. Monitoring and prevention.

Developmental disruptions, long-term impact of relatives' torture, Impact of witnessing torture in the community.

Developmental disruptions - infant torture (a) in country of origin (b) as a refugee.

The effect on caregivers of torture/kidnapping of their children.

Impact on identity and worldviews of torture in adolescents.

Trans-generational trauma. Define criteria. Preventive and therapeutic approaches.

Social cleansing Homeless people / Marginalized populations / People in social deprived areas (slums/favelas..) subject to torture as part of social cleansing policies.

Torture in the fight against narcotic crime control, human and drug trafficking, youth gangs.

Torture as part of initiation rituals for secret societies in the developing world.

Torture in the context of repression and control of social protests against social inequality and criminalization of protests and demonstrations.

Torture in the context of those disappeared and in extrajudicial killings (torture resulting in death - denial of information to relatives as torture-Evidence-based data for legal claims as torture). Long-term impact of ambiguous loss-Comparing impacts in relatives of detained/disappeared in the short term (e.g. Sri Lanka), middle term (e.g. South Africa, Chile) and long-term (e.g. Spanish mass graves of the Civil War).

Ill treatment and systematic violence by Non-State actors in context of war and civil war by private gangs, human traffickers, rebel or terrorist groups occupying territories.

Torture practices in western democracies as compared to oppressive regimes. Impacts.

Torture and migration. Torture linked to border control of refugees and in centres of detention of migrants. Comparative study between patterns of torture documented in countries of origin with those documented in countries of destination.

Traumatized refugees - evidence for psychosocial resilience and vulnerability factors (access to labour market, legal situation or having an identity as determinants of health). 
Political motivation as a protective or risk factor in torture survivors. Resilience and activism - comparing the impact of torture on activist and on partner/family member/non-activist.

Differences between those who fled and those who stayed in the country.

\section{New types of perpetrators}

35

36

37

38
The perpetrator in torture that is not part of an interrogation process.

The transition from perpetrator to victim and from victim to perpetrator.

Torture / ill-treatment in daily interactions and in wider contexts including in bureaucracies.

The psychology and social psychology of doing evil.

Places of Detention, Deprivation of Liberty. Specific aspects

39

40

41

43
Torture/Conditions that amount to torture in prisons. Reassessing minimum standards amounting to torture. Academic studies on the adequacy of CPT Standards and recommendations.

Documentation of torture in prisons. Refining methods for National Prevention Mechanisms and other monitoring bodies.

Solitary confinement as torture.

Conditions when punishment amounts to torture.

Places where torture actually happens: epidemiology of torture in short-term (i.e. police stations) versus long-term detention (i.e prison) centres. Should prevention focus more on early phases of judicial processes and less on convicted subject.

Police and social dissent

44 Police equipment. Use of teargas/Use of Taser guns

45

46
Standards of practice in the use of force by police. Police brutality amounting to torture.

Ill-treatment - Torture in demonstrations and other non-custodial settings. Role of doctors in the documentation of police brutality in demonstrations and barriers to the effective implementation of their role (i.e Bahrein, Turkey).

Examples of good practice, protocols and guidelines in police action.

\section{(2) ASSESSMENT}

\section{Neurobiology}


Biological markers for legal/forensic documentation of torture.

\begin{tabular}{ll}
\hline Neuropsychology & \\
\hline 52 & $\begin{array}{l}\text { Uses of neuropsychological test in the documentation of torture. Head trauma. } \\
\text { Minor brain injury. }\end{array}$ \\
& Neuroscience and rehabilitation.
\end{tabular}

\section{Psychometric Tools}

54

55

56

57

\section{Medical Diagnosis}

Transcultural tools to classify torture methods.

Cross-cultural / Transcultural tools to measure the impact of torture using a comprehensive perspective.

Critical review and updated data on psychometric tools widely used in the torture sector (i.e Harvard Trauma Questionnaire).

Neuropsychology/Psychometric tools in documenting deception, malingering or exaggeration in false torture survivors.

\section{Community Impacts}

\section{(3) MEDICAL ASPECTS}

\section{Psychological Torture}

Definition. Tools (and validation) for assessing psychological torture.

\section{Somatic Complaints}

61 Analysis of the relationship between psychological and somatic symptoms in torture survivors. Chronic pain. Chronic somatic complaints.

\section{Classification}

Alternatives to PTSD in the conceptualization of the impact of torture.

Emic/Ethnic definitions of illnesses associated to trauma and torture.

Functionality 


\section{(4) LEGAL/FORENSIC DOCUMENTATION OF TORTURE}

\section{Concept}

67

Controversies in the proper identification and recognition of victims. Who is to be considered a victim in transitional justice and legal claims?

\section{Capacity}

68

Map of forensic capacities globally. Countries where there is installed capacity for medical and psychological documentation of torture.

\section{Istanbul Protocol}

69

70

71

72

73
Balance of the Istanbul Protocol as a research and forensic tool. StrengtheningImproving-Interpretation Guidelines.

Tools for Credibility analysis of the allegations of ill-treatment or torture for supporting survivors' claims.

Use of IP in other forensic contexts- eg documenting assault, domestic violence, trafficking cases subjected to prostitution or servitude including violence.

"Evidentiary inflation". Judges applying criminal standards of "beyond reasonable doubt" instead of administrative standards of "reasonable assumption" in asylum claims. Implications and solutions.

Outcomes of IP. Impact of documentation of torture in the decisions of the judicial system. Does forensic documentation really impact judges in their decisions? Which elements are considered relevant?

\section{Good practices when resources or conditions are not optima}

74

75

76
Specificities of the IP with refugee population. Adapted versions for international protection claims / migrant detention centres.

Documentation of torture in context of collective/massive atrocities

Tools for quick documentation in police stations, pre-trial detentions and monitoring of prisons.

\section{Documentation in primary care}

Awareness and knowledge of the use of the IP in primary health care settings.

78

Adaptations of medico-legal documentation (i.e. documentation of injuries in general health care) to IP standards.

\section{Rejection} torture in the future- Scientific study of the "past-does-not-mean-future" argument as a basis for rejection (i.e. following up cases after being returned). 


\section{Post-Mortem Assessment}

80

Recent post-mortem findings in cases of death by torture (i.e. acute compartment syndromes after hanging or falanga).

\section{Innovations}

81

Use of information and communications technology for safely reporting torture and ill treatment and reaching more vulnerable populations.

\section{(5) TREATMENT - REHABILITATION}

\section{Definition}

82

83

\section{National Policies}

84

5

86

(

(

9

1

.

3

What "rehabilitation" of torture survivors means. Defining the field.

Providing rehabilitation services in dangerous settings (e.g., when under threat from the state; where torture is rampant, etc.).
Policy process in national settings. National legislation and relevant stakeholders related to prevention, rehabilitation and redress.

Nexus between torture and poor governance. Torture related to corruption.

Examples of national good policies in the application of General Comment \#3 on the Right to Rehabilitation. Examples of good national plans for integral care of torture survivors. Examples of negative experiences. Recommendations.

Reporting on State-sponsored-organised rehabilitation services-Compliance with General Comment \#3.

Minimum standards of good care. What do health professionals and survivors consider a minimum of "good access" to rehabilitation services for torture survivors?

Controversies in the right to rehabilitation-(a) The role of the State as direct provider or funder. (b) Public Health System versus Specialized Networks (c) Free Choice between State and Non-State providers of services.

Accessibility - rural / urban inequalities in access to rehabilitation services. Cost-efficient alternatives in contexts where no rehabilitation centres are available.

Best practices in ensuring sustainability of rehabilitation centers. Right to rehabilitation not depending on political debate.

Coordination between national Mental Health services (where available) and Torture Rehabilitation services

International consensual set of indicators to assess outcome of rehabilitation programs. Adaptation to different contexts and conditions.

Clinical and non-clinical indicators of efficacy for multi-sectoral-complex interventions.

Outcome indicators for psychosocial and community based programmes. 


\section{Psychotherapy}

96

Basic non-specialized interventions. Psychological and social counselling and Psychological First Aid as applied to torture survivors, especially in low-resource countries or emergency settings.

97

Psychotherapeutic approaches that work. For whom, for what, and under what conditions?. Implementation of Randomized Controlled Outcome Trials (RCT)

98

Naturalistic or quasi-naturalistic studies in psychotherapy research: systematic documentation, pre-post clinical trials and quasi-experimental outcome trials based on actual practices.

99

Beyond specific techniques. Non-specific factors in therapy. Relative contribution to a positive outcome in psychotherapy.

\section{Group Work}

100

Models of group work. From mutual support to complex trauma therapeutic groups.

\section{Family therapy}

101

Models of family interventions.

\section{Expressive and Body therapies}

102

103

104
Integrating health and psychological treatment. Pain, somatic expressions of suffering and torture.

Physiotherapy interventions based on evidence.

Expressive therapies (creative movement therapy, art, music) in the healing process.

\section{Medical treatment -Pharmacotherapy}

105 Knowledge transfer from best evidence. Special considerations for torture survivors.

106 Pharmacotherapy based on evidence.

107

Pharmacotherapy that work to target specific diagnoses or symptoms.

\section{Professionals}

108

109

110
Cost-effective treatment for non-specialists, especially primary care and community workers.

Identification and treatment of survivors by health professionals employed in detention centres.

Community torture treatment programs with paraprofessionals/community health works (using CETA or other intervention methodologies). 


\section{Community, Cultural and spiritual issues}

111

112

114

115

116
Beyond individual rehabilitation to community rehabilitation (in situation of collective trauma).

Interventions that include cultural meanings or ethnocultural treatments of dealing with the impact of torture (i.e. symbolic healing / symbolic therapies).

Spirituality and rehabilitation.

Psychosocial / Community healing and recovery practices. Transfer of knowledge from low and middle income countries.

Role of interpreters in rehabilitation. Training.

Training methods in cultural competence for staff. Cultural humility.

\section{Special Populations}

117

118

119

122

\section{Outcome measures}

123

124
Access to Care / Rehabilitation for people on the move

Ensuring rehabilitation to tortured asylum seekers denied protection.

Care for caregivers.

Positive and negative experiences in the work with torture survivors from LGBTI community.

Rehabilitation of torture victims in prisons and other places of detention. Determining factors for success of interventions.

From Detention to Community: Lessons Learnt in the Provision of Through care for Tortured Detainees, Prisoners, Ex-detainees, Ex-prisoners, and their families.

Proactive detection of tortured ex-detainees in the community and provision of help.

Long-term differences between those who receive rehabilitation treatment or not. Is it true that time heals?

Long-term outcome-Long-term effects of interventions-Cohort studies with survivors. Reactivation of symptoms. "Chronicity" in torture survivors. Factors leading to re-traumatization/"Chronification" (internal and external factors), Implications for public policies.

Going beyond clinical measures to include quality of life, rebuilding a life project, social, daily functioning and community cohesion etc.

Guidelines with Best Practices approaches/level of recommendation specific for torture survivors.

\section{Participation of survivors in design and evaluation of programmes.}


Survivor-informed outcome measures.

Survivors of torture and empowerment.

\section{Justice and Rehabilitation}

131

132

133

134

135

136

137
Intersection between justice and rehabilitation (for the positive or negative).

Impact of judicial interventions on individual well-being. Does access to justice improves quality of life?

Life between trials when in a legal proceeding. Instrumentalization of survivors when engaged in legal proceedings.

Impact of reparation versus reparation plus rehabilitation (when the states "repairs" only on material/economic grounds).

Rehabilitation and long-term peacebuilding.

Sociological impact of Justice (i.e. Argentina \& Chile as examples).

Retaliation on organizations and human right defenders serving torture survivors.

\section{(6) JUSTICE AND REDRESS}

\section{Victim's support}

138

140

141

142

143
Psychological impact of impunity. Paths to recovery where impunity prevails.

Confronting the perpetrator. Encounters between survivors and perpetrators.

Traditional cultural practices in the transitional justice process for perpetrators and survivors.

Psychosocial support to survivors during the legal process. Good practice protocols for survivors that act as witnesses in trials.

Fight against impunity as a healing process. Meta-analysis/review on the impact of justice on survivors' well-being. Protective and risk elements. Do-no-harm principles and recommendations.

The increasing role of witnesses in redress and the impact of increasing threats to witnesses.

\section{Intentionality} intentionality of perpetrators for legal procedures.

\section{Impunity}




\section{Compensation}

146 Victims' priorities regarding types of reparation

147

Redress and compensation for innocent people in prolonged pre-trial detention in unusual harsh conditions.

Torture \& Mass graves

148

Effective implementation of the International Consensus on Minimum Standards for the Psychosocial Work in Exhumation Processes for the Search for Disappeared persons.

\section{No repetition}

149

150

151

\section{(7) ETHICS}

Research

Ethical standards in documentation of torture.

153

Standards of dealing with data-protection. Data protection versus statistics on torture and data protection versus reporting on the outcome of projects to donors

Ethical standards in research with survivors and perpetrators.

Aftercare for researchers. Ethical implications in the use of students in torture research.

Transparency and accountability in the use of research funds. Standards of good practice

\section{Professional role}

Dual loyalty. Participation of health professional in torture-Passive support to torture. No documentation of evidence as complicity. Medical role in impunity. Dilemmas and solutions for doctors working under dual loyalty (e.g. the problem of daily attendance to isolated prisoners and clinical assessment of mental health impact of the isolation).

Dual loyalty in non-health professions. 


\section{Survivor's autonomy}

161

Survivor experience of documentation process. Challenging avoidance or respecting the survivor's autonomy - exploring the tension between the needs of the evidentiary process and how much disclosure is enough?

162

Ethical issues with use of technology and social media.

(8) SOCIOLOGY - POLITICAL ENVIRONMENT - ADVOCACY - PREVENTION

\section{Sociology of torture}

163

164

165

166

167

168

\section{History}

169

Historical evolution of torture. The transition to becoming more and more psychological.

\section{Political context}

Pre-conceptions - social construction of the concept of "torture"- how people perceive torture. Manipulation of the public opinion about torture; its nature, its impact on victims, families, communities etc.

Sociological barriers to rehabilitation of survivors.

Reasons for supporting /tolerating torture. Increasing support (political, legal, corporative and even social) to the use of torture as shown by polls and sociological studies.

Role of education in human rights (civil and military servants and general population).

Role of media (TV series, films, apps and video games...) in banalizing torture and increasing indifference (bystanders) /support to it.

Research targeting proposals to legalize certain forms of torture.
170

171

Patterns of torture based on political contexts and analysis of conditions where there is a heightened risk of torture?

Politics and the tightening of asylum law and policies (including mass deportation, increased detention, possibly harder to pass credible fear interview, discriminatory policies toward refugees and asylum seekers from certain religious or ethnic backgrounds). How to combat these changes to ensure protection of the rights and safety of torture survivors.

\section{Epidemiology}

172

Clinical records guidelines. Good practice and recommendations for databases

173

Reliable data on worldwide and country prevalence applying consensual criteria.

\section{Advocacy}




\section{Annex 2}

Panellists by round

Abosede Omowumi Babatunde, Aida Seif El Dawla, Andrea Northwood, Andrew Rasmussen, Amanda Williams, Barbara Conde, Barbara Preitler, Bettina Birmanns, Bhava Poudyal, Carlos Jibaja Zárate, Changho Sohn, Craig Higson-Smith, Daniel Savin, David R Curry, Dina Al Shafie, Edeliza Hernandez, Edvard Hauff, Emmanuel Sarabwe, Eugenia Mpande, Fabiana Rousseaux, Felicitas Treue, Frances Lovemore, Fredrik Saboonchi, Hans Draminsky Petersen, Helena Solà, Jens Simon Modvig, Jeroen Knipscheer, Jessica Carlsson Lohmann, Jorge del Cura Anton, José Quiroga, Juliet Cohen, June Pagaduan Lopez, Kathi Anderson, Kolbassia Haoussou, Leanne Macmillan, Lilla Hardi, Mandira Sharma, Marianne Kastrup, Mechthild Wenk-Ansolhn, Morris Tidball-Binz, Raija-Leena Punamäki, Ramesh Prasad Adhikari, Sebnem Korur Fincanci, Morris Tidball-Binz, Noemí Sosa, Nora Sveaass, Paul Bolton, Pau Pérez-Sales, Sara Fridlund, S. Megan Berthold, Solvig Ekblad, Tania Kolker, Uju Agomoh, Uwe Harlacher, Vera Vital Brasil, Vincent Iacopino, Wilder Tayler.

Note: This Annex does not represent an exhaustive list of the contributors as some panellists expressly did not give permission for their name to be included and permission was not given in some cases due to administrative or technical reasons. Even though names are set out here, some panellists saw their responses as a collective effort from their centres. 


\section{Annex 3}

Round 3 items in original order (not by priority) by socio-demographic data. Yellow denotes the top five priorities for each variable.

Item 1 Definition of torture. Evidence-based distinction between torture and CIDT.

Item 2 Beyond torture methods - Definition of Torturing Environments.

Item 3 Impact of torture by combined or cumulative impacts.

Item 4 Relation btw types of torturing environments, impacts on survivors and rehabilitation strategies.

Item 5 Use of sexual violence in individual torture for both women and men.

Item 6 Developmental disruptions, long-term impact of relatives’ torture, Impact of witnessing torture.

Item 7 Trans-generational trauma. Define criteria. Preventive and therapeutic approaches.

Item 8 Torture in the context of those disappeared and in extrajudicial killings

Item 9 Psychometric tools widely used in the torture sector (i.e Harvard Trauma Questionnaire).

Item 10 Concept/description/Indicators of psychosocial/community impact of torture.

Item 11 Definition. Tools (and validation) for assessing psychological torture.

Item 12 Relationship between psychological and somatic symptoms. Chronic pain. Somatic complaints.

Item 13 Tools for Credibility analysis for supporting survivors’ claims.

Item 14 Outcomes of IP. Impact in the decisions of the judicial system.

Item 15 Tools for quick documentation in police stations, pre-trial detentions and monitoring of prisons.

Item 16 What "rehabilitation" of torture survivors means. Defining the field.

Item 17 Providing rehabilitation services in dangerous settings

Item 18 Examples of national good policies for integral care of torture survivors. 


\begin{tabular}{|c|c|c|c|c|c|c|c|c|c|c|c|}
\hline \multicolumn{5}{|c|}{ Geographic Area } & \multicolumn{2}{|c|}{ Gender } & \multicolumn{3}{|c|}{ Primary activity } & \multicolumn{2}{|c|}{ Work location } \\
\hline $\begin{array}{l}\text { ASIA } \\
(n=3)\end{array}$ & $\begin{array}{l}N A+P \\
(n=7)\end{array}$ & $\begin{array}{r}\text { LA } \\
(n=8)\end{array}$ & $\begin{array}{r}\text { Africa + } \\
\text { MENA } \\
(n=10)\end{array}$ & $\begin{array}{r}\text { Europe } \\
(n=17)\end{array}$ & $\begin{array}{r}M \\
(n=18)\end{array}$ & $\begin{array}{r}F \\
(n=27)\end{array}$ & $\begin{array}{r}\text { Direct } \\
\text { Care } \\
(n=16)\end{array}$ & $\begin{array}{l}\text { Legal } \\
(n=10)\end{array}$ & $\begin{array}{r}\text { Academia } \\
- \text { Research } \\
(n=17)\end{array}$ & $\begin{array}{r}\text { Asylum } \\
(\mathrm{N}=16)\end{array}$ & $\begin{array}{r}\text { National } \\
(\mathrm{N}=24)\end{array}$ \\
\hline 3 & 0 & 13 & 10 & 5 & 11 & 4 & 7 & 10 & 5 & 1 & 12 \\
\hline 0 & 0 & 0 & 7 & 0 & 0 & 3 & 4 & 0 & 0 & 0 & 3 \\
\hline 53 & 9 & 3 & 0 & 14 & 17 & 7 & 5 & 0 & 24 & 9 & 14 \\
\hline 0 & 0 & 0 & 21 & 12 & 16 & 5 & 12 & 13 & 2 & 6 & 13 \\
\hline 30 & 3 & 23 & 22 & 12 & 7 & 22 & 21 & 20 & 9 & 16 & 16 \\
\hline 0 & 20 & 0 & 8 & 11 & 14 & 5 & 17 & 0 & 7 & 11 & 6 \\
\hline 30 & 27 & 54 & 8 & 16 & 14 & 30 & 46 & 1 & 16 & 29 & 25 \\
\hline 13 & 16 & 60 & 19 & 13 & 17 & 27 & 43 & 23 & 7 & 18 & 30 \\
\hline 50 & 23 & 3 & 31 & 16 & 24 & 18 & 11 & 9 & 34 & 23 & 16 \\
\hline 17 & 23 & 21 & 14 & 19 & 19 & 19 & 27 & 14 & 12 & 28 & 14 \\
\hline 0 & 17 & 0 & 16 & 6 & 9 & 8 & 11 & 3 & 8 & 3 & 11 \\
\hline 0 & 10 & 5 & 16 & 18 & 8 & 16 & 8 & 4 & 19 & 17 & 10 \\
\hline 43 & 19 & 9 & 19 & 4 & 11 & 14 & 4 & 25 & 12 & 11 & 18 \\
\hline 43 & 27 & 19 & 24 & 38 & 35 & 27 & 13 & 58 & 34 & 23 & 38 \\
\hline 0 & 20 & 19 & 17 & 19 & 23 & 14 & 18 & 22 & 16 & 13 & 21 \\
\hline 0 & 9 & 10 & 7 & 16 & 4 & 15 & 15 & 11 & 8 & 21 & 3 \\
\hline 0 & 27 & 15 & 28 & 19 & 16 & 23 & 23 & 16 & 21 & 18 & 18 \\
\hline 0 & 23 & 50 & 5 & 22 & 11 & 29 & 30 & 16 & 21 & 13 & 28 \\
\hline
\end{tabular}


Item 19 Minimum standards of good care in rehabilitation services for torture survivors

Item 20 Coordination between national Mental Health services and Torture Rehabilitation services

Item 21 Models of family interventions.

Item 22 Care for caregivers.

Item 23 Long-term outcome -Cohort studies. Implications for public policies.

Item 24 Survivor participation in research. Participatory action research.

Item 25 Survivors of torture and empowerment.

Item 26 Intersection between justice and rehabilitation (for the positive or negative).

Item 27 Impact of judicial interventions on individual well-being.

Item 28 Psychological impact of impunity. Paths to recovery where impunity prevails.

Item 29 Psychosocial support to survivors during the legal process.

Item 30 Fight against impunity as a healing process.

Item 31 The increasing role of witnesses in redress and the impact of increasing threats to witnesses.

Item 32 Victims' priorities regarding types of reparation.

Item 33 Effective implementation of Minimum Standards in Exhumation Processes

Item 34 Ethical standards in documentation of torture.

Item 35 Dual loyalty. Participation of health professional in torture - Passive support to torture

Item 36 Reasons for social supporting /tolerating torture

Item 37 Role of media (TV series, films, apps and video games...) in increasing indifference /support

Item 38 Patterns of torture based on political contexts

Item 39 Politics and the tightening of asylum law and policies

Item 40 Strategic use of clinical data for advocacy. Recommendations and guidelines. 


\begin{tabular}{|c|c|c|c|c|c|c|c|c|c|c|c|}
\hline \multicolumn{5}{|c|}{ Geographic Area } & \multicolumn{2}{|c|}{ Gender } & \multicolumn{3}{|c|}{ Primary activity } & \multicolumn{2}{|c|}{ Work location } \\
\hline $\begin{array}{c}\text { ASIA } \\
(n=3)\end{array}$ & $\begin{array}{l}\text { NA+P } \\
(n=7)\end{array}$ & $\begin{array}{r}\text { LA } \\
(n=8)\end{array}$ & $\begin{array}{r}\text { Africa + } \\
\text { MENA } \\
(n=10)\end{array}$ & $\begin{array}{r}\text { Europe } \\
(n=17)\end{array}$ & $\begin{array}{r}M \\
(n=18)\end{array}$ & $\begin{array}{r}F \\
(n=27)\end{array}$ & $\begin{array}{r}\text { Direct } \\
\text { Care } \\
(n=16)\end{array}$ & $\begin{array}{c}\text { Legal } \\
(n=10)\end{array}$ & $\begin{array}{r}\text { Academia } \\
- \text { Research } \\
(n=17)\end{array}$ & $\begin{array}{c}\text { Asylum } \\
(\mathrm{N}=16)\end{array}$ & $\begin{array}{r}\text { National } \\
(\mathrm{N}=24)\end{array}$ \\
\hline 27 & 30 & 4 & 22 & 19 & 23 & 16 & 10 & 26 & 22 & 19 & 16 \\
\hline 0 & 0 & 0 & 0 & 2 & 0 & 1 & 1 & 2 & 0 & 3 & 0 \\
\hline 0 & 14 & 8 & 28 & 14 & 16 & 14 & 14 & 14 & 13 & 23 & 10 \\
\hline 0 & 3 & 24 & 29 & 11 & 5 & 22 & 15 & 29 & 4 & 9 & 22 \\
\hline 13 & 27 & 61 & 12 & 45 & 43 & 31 & 42 & 0 & 55 & 41 & 37 \\
\hline 20 & 30 & 31 & 6 & 23 & 27 & 18 & 24 & 14 & 26 & 22 & 15 \\
\hline 10 & 6 & 4 & 14 & 15 & 15 & 9 & 8 & 14 & 14 & 13 & 8 \\
\hline 23 & 13 & 15 & 20 & 4 & 11 & 13 & 15 & 20 & 6 & 4 & 19 \\
\hline 70 & 13 & 8 & 8 & 4 & 12 & 11 & 6 & 11 & 18 & 4 & 17 \\
\hline 40 & 17 & 24 & 15 & 14 & 13 & 22 & 19 & 21 & 16 & 18 & 20 \\
\hline 0 & 19 & 34 & 25 & 20 & 22 & 22 & 33 & 30 & 10 & 16 & 24 \\
\hline 23 & 10 & 11 & 24 & 9 & 14 & 14 & 10 & 12 & 20 & 11 & 12 \\
\hline 0 & 0 & 0 & 0 & 0 & 0 & 0 & 0 & 0 & 0 & 0 & 0 \\
\hline 0 & 0 & 0 & 14 & 4 & 6 & 3 & 0 & 0 & 9 & 6 & 4 \\
\hline 0 & 0 & 8 & 0 & 11 & 3 & 7 & 0 & 6 & 11 & 12 & 3 \\
\hline 3 & 14 & 6 & 10 & 13 & 9 & 12 & 6 & 15 & 11 & 12 & 8 \\
\hline 30 & 21 & 0 & 10 & 9 & 9 & 12 & 11 & 7 & 14 & 11 & 9 \\
\hline 0 & 0 & 0 & 3 & 9 & 3 & 5 & 3 & 0 & 9 & 6 & 4 \\
\hline 13 & 4 & 0 & 0 & 8 & 7 & 3 & 2 & 15 & 1 & 8 & 3 \\
\hline 23 & 0 & 0 & 3 & 5 & 3 & 5 & 0 & 10 & 5 & 0 & 8 \\
\hline 0 & 31 & 3 & 11 & 17 & 24 & 8 & 6 & 28 & 13 & 16 & 8 \\
\hline 0 & 33 & 3 & 30 & 27 & 21 & 23 & 9 & 24 & 26 & 32 & 13 \\
\hline
\end{tabular}


Related to

Rehabilitation of

torture survivors

and prevention of

torture: Priorities for

research through a

modified Delphi

Study

\section{Comment I \\ Torture as a chronic disease}

\section{José Quiroga*}

The Delphi study presented here shows an apparently surprising first priority line for research in having lifetime data to consider the consequences of torture as a chronic disease. But this is not so surprising if we attended to the following facts:

- Torture is a very special and distinctive traumatic experience because of its severe physical and psychological suffering intentionally inflicted by another human being. Torture is also a socio-political trauma that is inflicted with the full force of the state over an individual. The State, instead of protecting the person, destroys him/ her. Both elements are unique and part of what we call extreme traumatization (Bettelheim, 1943)

^) Former Medical Director of Program for Torture Victims (PTV)-USA.

Correspondence to: JQuirogaMD@aol.com
- Additionally, most victims are powerless, and suffer hopelessness, being under the complete and total control of the perpetrator. The life or death of the victims depends arbitrarily on the decisions of others. The victims face impossible dilemmas, having to take impossible decisions that face them with betrayal and long-life shame or guilt. (Castillo, 1989)

- The classification of the psychological impact of torture is not well-collected by the standard World Health Organization (WHO) or American Psychiatric Association (APA) diagnosis of PTSD and/or depression. There are essential psychopathological and sociological elements which are not collected (Becker, 1995). We cannot consider the natural history of PTSD as representative of the evolution of the symptoms of surviving torture. As a physician, I have worked with survivors of torture since the military coup in Chile in 1973. In my 40 years of experience, I have learned that torture is a chronic, lifetime process for a significant number of victims who experience persistent anxiety, depression or PTSD symptoms, cognitive impairment, attentional deficits and memory problems.

- The symptoms can decrease with time, but reminders of the traumatic situation produce again significant distress and reactivation of symptoms. The traumatic experience of torture is reactivated.

- Furthermore, the principal physical complaint in many victims is chronic pain. Permanent scars on the body are visible in $40-70 \%$ of the victims, and serve to remind them of the traumatic event[s] (Scary, 1997). A small proportion suffer permanent disabilities such as seizure disorder or cognitive 
losses after traumatic brain injuries. In spite of these symptoms, the majority can function in society, but not without mental and or physical pain.

- Little information exists in the literature in relation to the magnitude and longterm recovery of torture survivors and their conditions for a full functional life. Clarification of the natural history and evolution of symptoms and factors of protection and vulnerability linked to reactivation are a mandatory area for future research, as suggested by the Delphi study we discuss here. A preliminary study of 28 victims who were tortured between 1973 and 1974 in the Pisagua detention center in Chile using the Istanbul Protocol and the Harvard Trauma Questionnaire (HTQ) showed that more than 40 years after torture $54.5 \%$ had pervasive symptoms of depression, $45.5 \%$ suffered anxiety, and $16.7 \%$ PTSD. The study showed a prevalence of all disorders significantly higher than in the general population of Chile.(Gomez-Varas et al., 2016). This is not surprising. A pioneering study with a sample of 276 Canadian World War II veterans (Beal, 1995) found that that fifty years after the end of the war $43.4 \%$ of the veterans presented with symptoms of PTSD (according to DSM III-R) as compared with 29.9 $\%$ of non-POW veterans. I have not done a systematic review of the topic, but judging by experience, this is what we would expect in other samples and I would encourage a meta-analysis of available data.

- We need to get more cohort studies on long-term consequences of torture. But also a study comparing treated and non-treated groups, to analyse the longterm impact of our therapies. Similar research, with wider samples and more sophisticated tools, and hopefully with comparison groups needs to be promoted in Argentina, Uruguay, and Brazil.

- We need also, to better understand the complexity and extreme situation of the torture victim, and to formulate a better approach to treatment, to do qualitative analysis and use, clinical descriptions that go beyond PTSD and are closer to psychopathology, biology and neuroscience of the brain.

Torture needs to be recognized as a clinically identifiable disorder. PTSD is not enough to capture its complexity - and needs to be identified, in those affected, as a chronic disorder. Today "torture" is only a legal definition and not considered a mental or medical diagnosis. This is a misconception and a gruesome error. In my view, this situation needs to change and cohort studies with survivors on long-term impact and treatment will cast light on this complex issue.

\section{References}

American Psychiatric Association. (2013). Diagnostic and Statistical Manual of Mental Disorders. Arlington. https://doi.org/10.1176/appi. books.9780890425596.744053

Beal, A. L. (1995). Post-traumatic stress disorder in prisoners of war and combat veterans of the Dieppe Raid: A 50-year follow-up. Canadian fournal of Psychiatry, 40(4), 177-184.

Becker D. (1995). The deficiency of the concept of Post-Traumatic stress disorder when dealing with victims of human rights violations. In Kleber RJ, Figley CR, Gersons B. (Eds). Beyond Trauma: Cultural and Societal Dynamics. Plenum Press. https://doi.org/10.1016/S02727358(96)00033-5

Bettelheim B. (1943). Individual and mass behavior in extreme situations. Fournal of Abnormal Social Psychology. 38:4717-452

Castillo MI, Gómez E, Kovalsky J. (1990). La tortura como experiencia traumática extrema, su expresión en lo psicológico, en lo somático y en 
lo social. In CODEPU Seminario Internacional

Tortura Aspectos médicos, psicológicos y sociales, prevención y tratamiento. Ediciones CODEPU

Gómez-Varas, A-G, Valdés J, Manzanero, A. (2016).

Evolución demorada de trauma psicológico en víctimas de tortura durante la dictadura militar en Chile. Revista de Victimologia 4:105-12.

\section{Comment II}

\section{A Palestinian view of the results of the Delphi study}

\section{Mahmud Sehwail*}

The results of the study provide an accurate and comprehensive way that make full sense from a Palestinian point of view. It is mostly true that torture victims really demonstrate a kind of chronicity, and shame has often be considered as a cardinal symptom of it. The remote consequences of torture appear in the form of family and social problems. The aim of torture is not to kill the body but to kill the soul and to spread fear in the person, family and in the whole community.

The majority of torture survivors we attend to suffer from multiple traumatic events or re-traumatization. At Treatment and Rehabilitation Center for Victims of Torture (TRC) we use the term Continuing Traumatic Stress disorder (CTSD) which leads to chronicity and makes treatment more difficult. Long-term consequences of trauma can affect the neuroplasticity of the brain and be evidenced by a reduction in the volume of hippocampus and an increase in the activity of the amygdala. It is an important theme how we link chronicity

*) President and Founder of Treatment and Rehabilitation Center for Victims of Torture (TRC), Consultant Psychiatrist.

Correspondence to: mahmud.sehwail@trc-pal.org with biological markers and find evidences of permanent brain damage. Many resources should be allocated to it to provide signals of the complexity of trauma and its remote sequelae in the context of torture that continues for decades, as in our region.

Besides this, it is always important to emphasize research on pragmatic and evidence-based methods of intervention rather than relying on classical lengthy methods of psychotherapy. At TRC we use different models of treatment. Many of our patients express their psychological symptoms in the form of somatic complaints. It is not strange to discover at a certain stage during primary health care that physical complaints are indeed psychosomatic and linked to torture. These are important aspects of research also. Medico-legal documentation, when conducted in a safe environment, is a key part of this process and can be considered as therapeutic as it includes retelling the traumatic story of torture to the therapist who acts as a witness. We at TRC use the Istanbul Protocol and agree that we need more research on it.

We would also like to stress the importance given in the study to the care for caregivers. This will provide an armour against burn-out and negative transference. At TRC, we organize occasional open days when the team gathers for free activities to prevent burn-out in addition to regular supervision. However, burn-out is an issue for us that deserves more research.

Finally, in the study, it was considered that empowering victims of torture regarding medical, psychiatric and psychosocial rehabilitation should be considered relevant and this matches our experience. This is an important part of the framework of international law to reintegrate victims into the society. However, empowering 
is also about providing vocational rehabilitation and helping the survivor to earn a living and this is not exactly reflected in the study despite our experience in this regard being very positive.

We would like to commend this exceptional work that can give important tips on old and new avenues for research.

\section{Comment III}

\section{Latin American priorities for research in the prevention and rehabilitation of torture}

\section{Carlos Jibaja Zárate*}

The Delphi methodology used in this outstanding research has allowed a wide group of experts from 23 countries from different regions of the world to reach 40 thematic axes, which have been agreed upon and weighted, generating a list of prioritized topics. There are several aspects that the study presents which I found especially remarkable: the dissociation between what we know, what we would like to know and what is being investigated; the predominance of applied over theoretical research; the notion of establishing regional priorities instead of unifying them on a global scale; the non-prioritization of more contemporary research lines such as those associated with gender perspective, neurobiology, updates to the Istanbul Protocol, the implementation and effectiveness of National Prevention Mechanisms, the use of new technologies among others.

\footnotetext{
*) Director of Mental Health Area. Centro de Atención Psicosocial (CAPS), Peru.

Correspondence to: cjibaja@caps.org.pe
}

I would like to comment, as a Peruvian, on the priorities for Latin America. These, in my opinion, accurately reflect the areas of interest shown by the centers that serve torture survivors. I feel fully identified. Research on psychosocial treatments for torture survivors that include a community and socio-political view with long-term follow-up and building appropriate indicators for that is clearly a priority. The socio-political and legal context that generates impunity and violence against survivors continues to operate in our countries, and these factors are behind the chronicity and recurrence of the symptoms and the difficulties in coping abilities of the survivor. Enforced disappearances and extrajudicial executions are legally typified in a different Convention (not that against torture), but there are many points in common in regard to the possible torture or death of the victim, as well as abuses and humiliations suffered at the hands of the State. Both are key elements in the rehabilitation of relatives and require emotional elaboration in the overwhelming majority of the cases. This is an under-researched and important topic in Latin America.

Likewise, our centers serve family members of third and even fourth generation victims, who apparently have conflicts disconnected from situations of intentional violence experienced by the survivor and the most direct family group (for example, intra-family violence), but when going deeply into the psychotherapy and the living conditions of the relatives, the causal relationships between the problems presented and the experiences of torture seem obvious. The experiences of horror and violence experienced by the survivor or her relatives, by not being emotionally tackled, 
can pass to new generations as traumatic burdens felt in the body, in interpersonal conflicts, as implicit family mandates, etc. We have a wealth of clinical and qualitative observations and a lack of strong research data that can foster rehabilitation programs and demand actions from the State.

The panelists have also prioritized the systematic study of national comprehensive care plans for survivors of torture as part of their right to rehabilitation: data on comparative experiences of national rehabilitation plans in countries such as Chile and Uruguay, to mention two examples, are important to learn what has worked and the importance of ecological, sociopolitical and cultural differences.

Finally, another priority is the accompaniment of victims during legal proceedings. The victim can be an individual, a couple, a group of people affected within a town, or a high Andean community, etc. who at the beginning of the legal process does not usually have a clear idea of how long and exhausting the process will be. It is important to systematize experiences on the work of therapeutic agents that serve as a point of support for the survivors as well as the legal team.

Identifying areas of research at a regional level, as well as having the possibility of systematically studying them, are tasks that are often postponed due to our sociopolitical and economic contexts in which we urgently need to direct attention to the survivor and the fight against impunity in public instances. This study takes a step in the right direction to contribute to concentrating efforts and resources in the investigation of what we do, what we are interested in investigating and what we need to know more about in the Latin American region. We hope this can be taken into account by fundraisers and donors and help in developing this research agenda in the following years to come.

\section{Comment IV}

Priorities for research

- a view from Russia

\section{Yakov Gilinskiy, PhD, Dr of Science (Law), Prof. *}

It would seem that the whole history of mankind screams against torture. But torture by police and prison staff continues in different countries. This topic, unfortunately, is very actual for Russia in the twenty-first century, where torture is systematically applied (Gilinsky, $2007 ; 2011)$. We welcome the initiative of Torture Journal. The main advantages of multi-center, multi-country research are its international character and generalization of results, complex, interdisciplinary nature, use of the latest methods in a shared way and, according to the priorities that arise from the Study, focus on practical results in order to reduce torture and provide assistance to people who have survived torture. I find the results of the study reliable due to the efforts to ensure the representativeness of panellists and an open research methodology. The process, through three rounds of consultation, allow for a reliable consensus and an agenda for shared research in the sector. Panellists included professionals (medical, psychologist and psychiatrists, lawyers, social workers and members of organizations of survivors) from 23

\footnotetext{
^) St. Petersburg, Russia

Correspondence to: yakov.gilinsky@gmail.com
} 
countries balanced by gender, geographical area, profession and area of work.

As a result of the expert rounds, the results highlight the importance of longterm outcomes and effects of interventions (including chronicity, factors leading to retraumatisation and implications for public health); outcomes of the Istanbul Protocol (impact of documentation of torture in the judicial system); trans-generational trauma; and, torture in the context of those disappeared and in extrajudicial killings. All of them relevant topics in Russia.

It is amazing that the research did not find significant differences in priorities by gender. I cannot think of a clear explanation for this. The extent and type of torture varies widely between countries. Therefore, it is not surprising that the analysis by "geographical area showed important peculiarities suggesting that a single worldwide agenda of research might not be realistic or desirable, and that local and regional priorities must also be taken into account". All the top priorities seem pertinent and worth researching: the definition of torture; specificities of contemporary torture and torturing environments; specificities of certain populations - sexual violence, children and transgenerational trauma, extrajudicial killings and forced disappearance; documentation of torture, and impact on the judicial system; definition of rehabilitation and good practices, measures, questionnaires; community indicators; empowerment of victims; impunity, justice and redress; ethical aspects; and political and sociological aspects. An important issue is how the state - the perpetrator of torture- provides help for the rehabilitation of victims of torture. An initial step for that is the recognition that torture exists, which is not the reality in some of our countries where it is denied by authorities. Of course, and linked to this, is one of the most important questions: how should the courts respond to torture claims during the investigation?

As a summary, I think that the study showed the most important problems of torture, assistance to victims of torture, and the results of the study can serve as the beginning of a series of collaborative research studies of these problems.

\section{References}

Gilinskiy Y. (2011). Torture by the Russian Police: An Empirical Study. Police Practice and Research. An International fournal, 12, N2, 163-171.

Gilinskiy Y., et al. (2007). Sociology of violence. Arbitrariness of law enforcement bodies by the eyes of people. Nizhny Novgorod: Committee against torture.

\section{Comment V}

\section{Do we have a holistic perspective of torture-related research?}

\section{Metin Bakkalcı, MD*}

This is an invaluable study conducted with the contribution of many experts. Bringing together the leading professionals in the field and adopting an interdisciplinary approach, I am sure this study will make a significant contribution to the literature on the subject, will strengthen the existing studies, and will open new horizons for all of us. I want to share my first unstructured impressions to the results.

I am surprised about the little importance given by the panellists to medical aspects of torture. Unfortunately I had the impression that for the experts, rehabilitation is reduced to its psychological aspects alone. I feel like the lack of a holistic

*) Secretary General, Human Rights Foundation of Turkey (HRFT)

Correspondence to: mbakkalci@tihv.org.tr 
understanding of rehabilitation (especially, the absence of importance given to physical complaints, medical findings, diagnosis, treatment process and reporting and also all social approaches linked to these points) is an important lacuna here. The true understanding of holistic rehabilitation stated in CAT General Comment 3 should include medical and psychological care as well as legal and social services.

I am afraid that the way the authors ordered topics in categories might have weakened the reliability of the results by not giving proper emphasis to medical aspects. This is also reflected in the discussion, where again I am surprised by the dominance of the psychological perspective.

I am concerned by the fact that the Istanbul Protocol is scarcely mentioned as a research priority and it is considered as a tool for forensic documentation of torture. I prefer to use the term "medical" and avoid "forensic", as this might lead to the wrong impression that such an evaluation can only be conducted by a certified forensic expert or a government expert. In fact, all the medical professionals in this field should use and respect the Istanbul Protocol as a shared unified tool. We need a wider medical perspective here.

I would also like to express some concerns regarding the distinction between the categories "assessment in country of asylum versus where torture was perpetrated" and "whether the panellist works in a country of asylum or a refugeeproducing country". Both expressions are problematic and ignore that torture is also a practice in these "countries of asylum", including Europe and the US, bearing in mind, for example, the European Court of Human Rights sentences condemning different European countries for practices considered as amounting to torture.
Furthermore, the distinction between country of asylum and refugee-producing country is problematic in practice. As a person writing from Turkey, we are providing services to persons predominantly tortured in Turkey and living in Turkey, a country also hosting 3.3 million Syrian refugees. It might be that there are not noticeable differences in priorities because these categories need a conceptual revision.

I would like to mention two additional points: the complexity of the idea of "building an identity around victimhood" and in which sense this is produced by the trauma itself, but also by the purely traumafocused approach of medical professionals. I believe that turning "victimhood" into an identity -and sometimes the main identityfor torture survivors who actually have a wide array of experiences alongside the experience of torture, encloses the survivor into a "torture victim".

Importantly, the concept "psychological torture" would need further clarification, as far as it is well-known and mentioned in Istanbul Protocol (Paragraph 145) that the distinction between physical and psychological methods is artificial. This is a major topic, but before proposing research on psychological torture as a priority, some conceptual clarification is needed.

From a more general stand I would also suggest the use of the concept "anti-torture movement" (which is also used in the study) instead of the concept of "anti-torture sector".

Finally, I have to state that I am very glad to read in the discussion that "the obsession for so-called evidence-based treatments and guidelines of good practice shown by some academia and especially by funders, seems not to be shared by most of the experts." In treatment and rehabilitation services, our utmost priority and focus should be improving the physical, 
psychological and social well-being of torture survivors, rather than satisfying funders through numbers. Considering the absolute prohibition of torture, the need for an apology and the right to full redress are the highest priority, and as the authors suggest, our circles should be more sensible to this deep political perspective with an emphasis on human rights' values.

\section{Comment VI}

\section{Response to Delphi Study: reflections from Zimbabwe}

\section{Frances Lovemore, MD*}

The political terrain of Zimbabwe has created a complex environment for both survivors of torture and their families and for the health and legal professionals providing treatment, rehabilitation and access to reparations and justice, as limiting impunity contributes to prevention of torture.

Torture prevalence in Zimbabwe is directly correlated to political threat, the conflation of the state and the ruling liberation party, ZANU PF, which retains political control through intimidation and targeted torture of activist and opposition leaders and members. Many survivors have been targeted and tortured on numerous occasions over decades in close proximity to their abodes. The economic reality of Zimbabwe forces them to return to their homes and live among the perpetrators, who are ever present and reactivated as required by the state/ruling party. The chronicity of the prevalence of torture

^) Director, Counselling Services Unit, Zimbabwe Correspondence to: franlovemore@gmail.com combined with the limited health care services and the prevalence of both communicable and non-communicable disease contributes to challenges with regard to holistic rehabilitation and monitoring of impact of interventions with regard to treatment. The other limiting factor with regard to rehabilitation interventions is access to services. The risk to clients' and their families' safety seeking treatment and rehabilitation can limit the number of times the client can attend the clinic.

Torture is prohibited under Section 53 of the Constitution of Zimbabwe Amendment (No.20) Act 2013, but is not criminalised. Nor has Zimbabwe signed the UN Convention against Torture. Perpetrators are therefore charged with "causing grievous bodily harm" in the criminal justice system, and in the civil litigation system can be found guilty in terms of the constitution and forced to pay compensation. Since 2000, when the Istanbul Protocol was declared the official United Nations guideline to treatment and documentation of torture, the protocol has been used by both the medical and legal responders to torture victims.

In this complex landscape, the outcomes of the Delphi study fit strongly with the prevailing conditions in Zimbabwe and indicate that the research work in Zimbabwe can contribute significantly to a global agenda of research with respect to the topics chosen as top priorities. The agreed ten research priorities dovetail neatly with on-going work with survivors and can be calibrated to suit a broader range of research capabilities in small centres participating in research projects.

The data available in Zimbabwe is rich and detailed. It is of utmost importance to carry out an empirical analysis of the strategic use of data for advocacy. This can have a direct positive impact in outcomes 
for torture survivors. The clinical records of survivors provide a comprehensive record of progress and challenges faced in the provision of services and their impact in an unstable environment. Also, as the study suggests, doing research on the use of the Istanbul Protocol that could contribute to a comparative analysis of the effectiveness of forensic medico-legal records. Also the impact of psychosocial support during legal processes, mentioned in the study, has been observed to be effective in Zimbabwe, and a research project is in fact underway in our Unit to evaluate the impact of the support.

We also give utmost importance to another point stressed by panellists: empowering survivors. Survivors have assisted in developing their rehabilitation programs at our Unit, and the next logical step is to also involve them in setting research priorities within the Zimbabwe context.

Finally I must mention the first-ranked topic: Cohesive studies on the long term impact of torture on communities and society and the imperative to provide comprehensive access to rehabilitation as defined by General Comment \#3 on a longterm perspective. Research on this important topic could provide the body of evidence required to ensure that the adequate provision of services to survivors and their communities, including reparation, remain or become a key priority of governments and donor agencies and that freedom from torture remains a benchmark in the human rights evaluation of countries.

With the research priorities now defined by this seminal study, I see possibilities to utilise well-established program work to contribute to multi-centre collaborative research for relatively little cost, and for centres to be able to accept a research component into their daily work and contribute to multi-centre studies and advocacy activities. The high cost of certain types of research such as neuro-biological research is inappropriate in many centres, as ours, where resources are extremely limited and the survivors' needs are wide-ranging and complex, and likely to be long-term. The Delphi study highlights that applied research to practical problems is possible in all centres, but particularly in low resource centres.

\section{Comment VII}

\section{Reflections on priorities and the way forward}

\section{Jens Simon Modvig*}

The Delphi study presented above provides very interesting results in terms of research priorities within the torture field, ie prevention of torture and rehabilitation of torture victims. Among the four top priorities, two have to do with the impact of interventions: (i) the long-term impact of rehab interventions in terms of preventing chronicity and re-traumatization, and (ii) the impact of doing medico-legal documentation of torture. The third highlighted area (although the second in priority) deals with the impact of torture across generations, ie the transgenerational impact of torture and the fourth relates to further research on forced disappearance as torture.

An important question in this connection is: What makes experts give priority to a particular research area? Immediately, one would assume that priorities are knowledgebased, that is, proposed research priorities

\footnotetext{
*) Director of Health Department, Chief Medical Officer in DIGNITY - Danish Institute Against Torture. Chair, UN Committee against Torture Correspondence: JMO@dignityinstitute.dk
} 
represent the knowledge that we do not have but would like to have. This could be based on a basic scientific approach, ie, we lack knowledge to understand the field better. However, another possibility is offering itself: Knowledge and arguments are needed in the practical (or operational) work against torture. This could be in advocacy work or in direct interactions with agents like courts, prosecutors, prison authorities or other Criminal Justice Authorities.

The main prioritized topic-longterm impact of interventions-serves as guidance to the rehabilitation movement. It will provide knowledge as to which interventions are effective, and which factors and interventions prevent chronicity. Such knowledge will sustain the right to rehabilitation and strengthen the arguments that all States parties to the UN Convention against Torture must establish rehabilitation services which are available, accessible, and appropriate. The better the knowledge of how to provide long-term effective interventions is founded, the better are the arguments for the State to actually establish such interventions. From a public health point of view, it would be highly relevant to document the long-term health economic benefits of early interventions and counteract the development of chronically incapacitated victims with heavy symptomatology and limited or no ability to contribute to societal development. It has to be added that rehabilitation services in states which recently perpetrated torture, are most often not considered appropriate by victims, and other solutions have to be found.

The impact of using the Istanbul Protocol in the fight against torture is the second most prioritized research topic. The reason behind that may be that we need more evidence to the extent that a solid medico-legal documentation of torture cases actually leads to convictions of perpetrators or redress to victims. While we have recently seen evidence that a preventive approach to fighting torture is in fact effective, it remains to be demonstrated that fighting impunity is an effective strategy to fight torture. We all believe that a well-prepared court case-in this case including good Istanbul Protocol compliant documentation-has better chances of winning than a case of alleged torture with no corroborating medical evidence. However, it remains to be seen how much better the chances of winning the case, and this is highly relevant knowledge for all involved with litigation of cases of torture. A particularly relevant question is which parts of the Istanbul Protocol examination makes a difference in the court's decisions. Research might contribute to this knowledge. A situation of increasing interest is prosecution of cases of alleged torture with no physical marks. Such cases pose challenges to the persons documenting the cases in order to provide corroborating medical/mental health evidence.

The fourth most prioritized topic is research into torture in the context of enforced disappearances and extra-judicial killings. This field is highly important but very difficult to research. Nobody with knowledge about torture would doubt that many or most cases of enforced disappearances also include torture, and that the same applies to extrajudicial killings. Especially, if we look at the fundamental legal safeguards on arrest (the right to legal counsel, the right to call upon a medical doctor and the right to inform relatives about the arrest) - rights which are considered the most important measures to prevent torture. The absence of these rights is characteristic of incommunicado detention which may lead to enforced disappearances. However, there is silence 
surrounding these cases, and getting reliable information of the true course of events, including the use of torture, is demanding. In particular, the impact of enforced disappearances on the relatives should be highlighted as an indirect way of inducing severe pain and suffering of relatives. Such research would most likely have to start as case-based research — presenting single cases of enforced disappearances or extrajudicial killings, where the component of torture had been revealed based on testimonies or autopsy findings.

While such case stories exist, there is no systematic research to build a consistent relationship between these phenomena. At the policy and prevention level, such research efforts should be supported by the UN Committee against Torture, the Committee for Enforced Disappearances and the Working Group for Arbitrary Detention.

In conclusion, the Delphi study seems for the first time to have pinpointed highly relevant research priorities within the scientific and practical work against torture. These research priorities could form the backbone of an internationally agreed research agenda. For this to happen, stakeholders would have to get together and discuss and adopt a common research agenda, preferably with the presence of donors within the field. I can only encourage stakeholders to take such an initiative-a workshop - to facilitate that research within the torture field pulls in the same direction.

In this context, key players such as the Torture Journal, IRCT, the Committee against Torture, research organizations like DIGNITY and CVT, and universities involved with torture-related research now have the initiative. 